Article

\title{
Determinants of Different Types of Positive Environmental Behaviors: An Analysis of Public and Private Sphere Actions
}

\author{
Ralph Hansmann ${ }^{1,2, *(\mathbb{D})}$ and Claudia R. Binder ${ }^{1, *(D)}$ \\ 1 Laboratory for Human Environment Relations in Urban Systems (HERUS), Mobiliar Chair in Urban Ecology \\ and Sustainable Living, École Polytechnique Fédérale de Lausanne (EPFL), 1015 Lausanne, Switzerland \\ 2 Transdisciplinarity Lab (TdLab), Department of Environmental Systems Science (D-USYS), Swiss Federal \\ Institute of Technology (ETH Zurich), 8092 Zurich, Switzerland \\ * Correspondence: ralph.hansmann@env.ethz.ch (R.H.); claudia.binder@epfl.ch (C.R.B.); \\ Tel.: +41-21-693-9362 (C.R.B.)
}

Received: 13 August 2020; Accepted: 11 October 2020; Published: 15 October 2020

\begin{abstract}
A survey of 1206 participants investigated determinants of positive environmental behaviors (PEBs) in Switzerland. Based on a principle component analysis on data for 23 different PEBs, three behavior types were distinguished: (i) public sphere PEBs with politically mediated impacts; (ii) socially salient private "lighthouse" PEBs that convey a pro-environmental message; and (iii) less socially salient private PEBs. An environmental behavior model identified general environmental knowledge and attitudes as the strongest predictors of PEBs, followed by green self-identity, justifications, assumed consequences, prescriptive social norms, gender, age, and perceived behavioral control (PBC), respectively. To promote sustainability-oriented behaviors and achieve corresponding societal and economic changes, the identified psychological factors need to be promoted by education and communication strategies as well as complementary measures ranging from policy changes to technology development and systems design. Green self-identity turned out to be significantly more influential for private PEBs than for public sphere PEBs, whereas prescriptive social norms and environmental knowledge were more important for public sphere PEBs. These findings indicate that promoting different types of sustainability-oriented behaviors may require distinct strategies. Public sphere PEBs may be enhanced well by conveying social practices and norms, whereas the promotion of a pro-environmental green self-identity may increase private sphere PEBs effectively.
\end{abstract}

Keywords: environmental behavior; private sphere; public sphere; environmental citizenship; justification; green identity; behavior determinants; intervention mapping

\section{Introduction}

The world is currently facing a severe environmental crisis as increasing consumption, land use, forest degradation, desertification, and $\mathrm{CO}_{2}$ emissions change the world climate and lead to environmental degradation with severe economic and humanitarian consequences [1-3]. A societal transformation in line with sustainable development goals is therfore urgently needed on local and global scales to counteract climate change, environmental pollution, and the depletion of natural resources and safeguard the quality of life and satisfaction of the needs of current and future generations $[4,5]$. In order to be successful, such a transformation will require encompassing technological, economic, behavioral, value-oriented, and socio-political changes taking the form of a fundamental paradigm shift leading to a society endorsing the principles of sustainability [6-9]. Though changes on economic and political macro-levels are required for achieving such a transformation, the role of people is crucial in this process [10-15]. Ultimately, individuals' environmentally significant 
decisions and behaviors form the basis of what will be reflected on an aggregated level in the reorientation of political, social, economic, and consumption processes and technologies toward greater sustainability and environmental protection [16-18]. Individuals act privately, for example, as family members and as consumers; they act as members of organizations as agents and employees; and they act socio-politically as citizens with social, political, and environmental responsibilities, for example, as voters or environmental activists $[19,20]$. In all these contexts and roles, individuals can help to prevent negative environmental devlopments and contribute to a change of society towards a path leading to a more sustainable future with healthy natural and environmental systems and enduring economic prosperity that is not based on an exploitation of the environment but rather on a symbiotic coexistence and on synergies between natural systems and economic activity. Human activity and natural systems are engaged in complex interactions as described in theories of socio-ecological system (SES) or human environment systems [21,22]. Both natural systems and social systems are very heterogenous entities that possess multiple macro and micro levels that can be ordered on scales with interrelated functional units [23]. So, for example, human society can be thought as consisting of human systems ranging in their scale from individuals over families and groups, to communities and national entities with economic, educational, scientific, social, and further subsystems [24]. Multi- and transdisciplinary research efforts involving all branches of science are required to improve our understanding of SES and generate solutions that allow socio-technological and behavioral transformations towards more sustainable societies and economies [25]. However, a disciplinary perspective may sometimes be helpful to decrease complexity and generate information that can be fed afterwards into more transdisciplinary scientific, technological, and socio-political problem-solving processes. In line with the latter reasoning, this study will take a primarily psychological perspective on sustainability and human behavior. An important aim of sustainability-oriented psychological research is to increase our understanding of processes leading to responsible environmental behaviors of individuals in their private consumption decisions and in their role as citizens of socio-political systems. Corresponding insights regarding the drivers of individuals' ecologically positive environmental behaviors (PEB) are crucial for the effective promotion and facilitation of responsible behavior through education, campaigns, technology development, and systems design.

\section{Theoretical Background}

Previous theories and related empirical findings on the determinants of environmentally significant behaviors represent the theoretical background of this study and will be described in the following. Thereafter, specific goals and hypotheses of this study are outlined.

\subsection{Understanding Environmentally Significant Behavior}

Manifold theories and behavioral decision-making models have been developed to increase our understanding of the determinants and processes influencing environmentally relevant behaviors of individuals. The field theory of Lewin [26] can be considered as a starting point in this regard. It postulated that human behavior is influenced by internal variables such as attitudes, values, and knowledge and external variables representing aspects of the physical and social environment of a person. In the 1970s, the norm-activation model (NAM) [27] was developed, which emphasized that social norms of positive environmental behaviors are conveyed to individuals in education and social learning processes so that they eventually become internalized by them. The resulting personal norms then trigger positive environmental behaviors, if individuals recognize their responsibility and are aware of the consequences of their actions. The NAM stimulated and guided a vast number of environmental behavior studies and is still applied, e.g., [28-32]. Currently, manifold psychological models of environmentally significant behaviors, such as, for example, the theory of interpersonal behavior (TIP) [33-35], the model of responsible environmental behavior [36-38], the motivation-opportunity-ability model $[39,40]$, the focus theory of normative conduct [41-43], and the value belief norm theory $[19,44]$, coexist. The presumably most frequently applied approach, 
however, is the theory of planned behavior (TPB), which considers attitudes, subjectively perceived social norms, and perceived behavioral control as crucial determinants of behavioral intentions and environmental behavior [29,31,45-51]. The diversity of these models, which partially overlap and are partially also open for the inclusion of additional determinants, makes desirable an integrative framework aiming at a reconciliation of these models. Aiming at an integrative synthesis of such theories and models, Stern [20] summarized the different variables used to explain and understand environmentally significant behavior of individuals and ordered them into different categories to build a corresponding framework. In his view, an encompassing, integrative model of environmentally significant behavior needs to consider four categories of determinants:

(i) Personal motivational factors: These include psychological constructs such as attitudes, values, personal needs, and goals, behavioral outcome beliefs, and personal evaluations or subjective expected utilities of behavioral outcomes.

(ii) Contextual forces: External social (e.g., roles, norms, laws, power, group dynamics, social influence and interactions, persuasion, role models), physical, and situational factors (e.g., distances, logistic aspects, external restriction and options).

(iii) Personal capabilities: Immaterial and material aspects such as knowledge, competencies, experience, environmental literacy, financial means, available time, social status, and power

(iv) Habits, routines, and reminiscences of past behaviors.

Previous findings of studies investigating the effects of prominent psychological constructs within these categories shall be briefly reviewed in the following.

\subsubsection{Personal Motivational Determinants of Pebs}

Environmental Attitudes

According to numerous previous studies and various existing psychological models such as TIP and TPB, environmental attitudes represent a crucial determinant of environmental behavior [29,31,33-35,45-58]. According to meta-analyses of studies applying the TPB positive environmental attitudes are substantially positively related to PEBs and often turn out to be the strongest predictor of corresponding intentions [49-51]. It is known, however, that the specificity of attitudes in relation to the environmental behaviors in question plays a role here. If a specific environmental behavior shall be explained, then behavior specific attitudes tend to have a higher explanative power than general environmental attitudes [45,46].

\section{Green Identity}

Self-identity refers to the idea that a person has of her- or himself, i.e., their self-concept of the goals, life-style, and behaviors that are appropriate and typical for his or her kind of person. Having a green identity is closely related to an individual's environmental attitudes and values. However, theories on self and social identity [59,60], including the TIP [33-35] and a considerable body of corresponding previous research, show the important role that a green self-identity plays as a distinct and powerful explanatory variable of environmental behavior $[58,61-66]$.

\section{Positive Affect}

The emotions and affect connected to the performance of a behavior are crucial motivational forces driving behaviors in diverse domains. Affect is included as an explanatory variable in the TIP [33-35], and many studies on environmental behavior have highlighted the important facilitating role of positive feelings for performing PEBs [67-69]. 
Awareness of Consequences

The awareness of consequences represents a belief in the instrumentality of PEBs to safeguard the environment. This variable is considered a crucial determinant of behavioral decision making according to the NAM [27-33] and the value belief norm theory [19,44]. Perceived behavioral effects are also related to self-efficacy expectations and play a central role in determining behavior according to social cognitive learning theories [70-72]. Therefore, it seems important to include the awareness of consequences in integrative environmental behavior models.

Justifications

Justifications have been acknowledged as an important factor explaining the gap between personal norms and actual behaviors. Sykes and Matza [73] developed the so-called neutralization theory, which explains such inconsistencies as deriving from justification processes that neutralize personal norms in a given context and situation and thereby protect individuals from self-blame when violating social norms that they basically accept [74-76]. The concept of psychological justifications was originally developed and applied in criminological research and was later transferred to the domain of environmentally significant behaviors, and they have consistently proven to be crucial determinants of behavioral decisions [77-84]. Justifications can trigger a moral licensing process that increases the intention-behavior gap between positive sustainability-oriented intentions and behaviors [85-88]. These findings suggested the incorporation of the acceptance of justifications for not behaving in an environmentally friendly manner as a determinant to be considered in this study.

\subsubsection{Contextual Forces Determining Pebs: Descriptive and Injunctive Social Norms}

Social norms are a crucial factor determining environmental behavior; this variable is universally acknowledged in environmental behavior models, and its importance has received substantial empirical confirmation. The TPB includes such social influences in the form of subjectively perceived social norms, and this so-called subjective norm component has been proven to be a significant predictor of a broad range of environmental intentions and behaviors [45-51]. According to the focus theory of normative conduct, it is necessary to distinguish between injunctive (prescriptive) social norms, which denote how people should behave, and descriptive social norms, which describe how people usually behave $[41-43,89]$. These two types of norms can be related to informative and normative social influence processes as basic determinants of behaviors in social contexts [90-94]. However, descriptive and injunctive social norms have not been explicitly distinguished in most previous studies employing environmental behavior models. Accordingly, it seems promising to differentiate between these two types of social norms in behavioral decision-making models.

\subsubsection{Personal Capabilities Determining Pebs}

Environmental knowledge, education level, perceived behavioral control (PBC), and income were incorporated into the model as possibly influential behavior determinants related to personal capabilities. The positive role of environmental knowledge and education level as facilitating determinants of PEBs have been confirmed in various previous studies [36-38,95-97]. Accordingly, it seems crucial to include knowledge as an explanatory variable in integrative environmental behavior models. The relationship between income and PEBs is less clear, as previous research obtained mixed findings in this regard. Evidence indicates that higher income is positively associated with costly PEBs such as organic food product purchases $[98,99]$. However, there are also many PEBs that tend to save money, and the environmental footprint of wealthier persons is often more negative due to generally higher levels of consumption. It therefore appeared promising to investigate whether different types of behavior might be differentially influenced by income levels in the present study. 


\subsubsection{Past Behavior and Further Variables Determining Pebs}

Past behaviors represent a statistically powerful base-line predictor for future behaviors, particularly if other influence factors remain stable [45,46]. However, interpreting past behavior as a determinant of future behavior could lead to tautological, circular explanations-in the sense of "someone did something because he or she did so in the past." Past behavior therefore has a special status among determinants of future behavior in that it needs to be distinguished from underlying psychological determinants of behavior. Like in many previous questionnaire studies, self-reported past PEBs served as a dependent variable rather than a predictor of PEBs in this research. Accordingly, a review on the role of past behavior and formation of habits is omitted here as corresponding information is provided elsewhere [100].

Finally, demographic variables can be related to PEBs. There is substantial evidence showing higher levels of PEBs among females than males in a broad range of behavioral domains [101-103]. Likewise, various studies show relationships between age and environmental attitudes and behaviors though the corresponding findings are heterogeneous [63]. Accordingly, it seems recommendable to also include demographic variables like gender and age in behavioral decision-making models. Obviously, age and gender do not represent psychological constructs, but they can serve as additional control variables in psychological models that could be related to personal motivational factors, external factors, and personal capabilities that are not sufficiently covered by other variables of a model. There exists a very large number of psychological constructs with potential influence on environmental behavior, and corresponding models, therefore, tend to be non-exhaustive. For the same reason, the lis of variables and psychological constructs described above represent a non-exhaustive selection. Some important predictors addressed in previous research are missing (e.g., environmental values, personal norms, social roles, or personality traits such as locus of control, introversion, emotional stability, etc. $[27-35,104,105])$ because it does not seem possible to address all of them in one single study.

\subsubsection{Different Types of Pebs and Their Determinants}

Aiming at an encompassing theory of environmentally significant behavior, Stern [20] furthermore distinguishes different types of environmentally significant behavior: (i) private environmentally significant behaviors that have a direct environmental impact (e.g., consumer behavior, recycling and waste disposal, mobility behavior, etc.); and (ii) public sphere behaviors that only indirectly impact the environment through politically and socially mediated processes (e.g., signing a pro-environmental petition, taking part in demonstrations, voting for ecologically oriented parties, persuading others in political discussion). Stern assumes that different factors may determine these two types of environmentally relevant behaviors, whereby "environmental concerns are within awareness and may therefore be influential" in the public sphere [20] (p. 409). Empirical evidence supports a differentiation between private and public sphere behaviors, and preliminary findings indeed evince a particularly high importance of environmental attitudes as determinants of public sphere PEBs [19,20]. This seems also well reconcilable with a more recent study by Liobikienè and Poškus [106], where an ecological worldview had a significant effect on public sphere PEBs, but not on private PEBs. Still in another study addressing public and private sphere behaviors, attitudes related to the perceived cost and importance of specific PEBs proved to be influential for both types of behaviors with in tendency higher path weights of importance aspects resulting for private PEBs and higher path weights of cost aspects for public PEBs [107].

Further findings of the study by Liobikienè and Poškus [106] were that action-related environmental knowledge had a positive significant effect only on private sphere PEB, but not on public sphere PEB, and that awareness of behavioral consequences likewise proved only to be significantly related to private sphere PEBs but not to public sphere PEB. However, perceived environmental responsibility influenced both types of PEB to a similar extent positively significant.

In a study by Huang, self-efficacy expectations-which entail aspects of awareness of consequences-proved significantly positively related with similar strength to both private PEBs and 
promotional public sphere PEBs [108]. A study by Tam and Chan [109] found that having a future orientation has a positive effect on public sphere PEBs but not on private sphere PEB, which has been explained by the authors to have a more indirect impact on public sphere PEB that takes longer to realize. A study by Kilbourne et al. [110] found environmental concern to be significantly related to both private sphere and public sphere PEB in similar strength.

On the background of these previous findings, additional research is required to explore the differential roles of other environmental behavior determinants in public and private behaviors. A consideration of the private and socio-political public spheres as two important domains of environmental engagement is also reflected in the concept of environmental citizenship behavior, which can be defined "as the responsible pro-environmental behavior of citizens who act and participate in society as agents of change in the private and public sphere on a local, national and global scale, through individual and collective actions in the direction of solving contemporary environmental problems, preventing the creation of new environmental problems, achieving sustainability and developing a healthy relationship with nature" [52] (p.8).

Distinguishing different types of PEBs and investigating which factors are crucial for their explanation and prediction is an important step towards the further development of our understanding of the determinants of environmental behavior. Despite previous efforts, there clearly remains a research and knowledge deficit in this regard. One reason for this gap is that the overwhelming majority of previous research focused either on the explanation of PEBs in general terms [53,54], or focused on rather specific behavior domains such as recycling behavior [55], organic food consumption [51,58], use of public transport [101,111], and other relatively narrow topical areas. A theoretical synthesis and integration of various specific behaviors into classes of behavior types and an investigation into their distinct determinants as suggested by Stern [20] are still largely missing. Therefore, this study aimed to further develop a corresponding knowledge base in order to better interconnect general theories of environmental behavior with empirical findings on specific behaviors.

\subsection{Study Aims and Hypotheses}

\subsubsection{Application of an Integrative Environmental Behavior Model Based on Previous Research}

An encompassing integrative behavioral model was developed for the application in this study. This analytic model was based on Stern's [20] classification of behavior determinants and on the findings of previous environmental behavior studies as outlined in the previous sections. The construction of the analytical framework thus followed an eclectic approach towards the selection of variables for each class of determinants, and the resulting model is depicted in Figure 1. The development of an integrative model with high explanative power was aspired and represents one aim of this study. However, taking an eclectic approach implies that the list of variables included in the overall model is by no means exhaustive. Still, based on the previous studies cited in Sections 2.1.1-2.1.4, it could be expected that all predictors included in the analytic framework of Figure 1 have the potential to contribute to the explanation of variance of environmentally significant behaviors. However, no explicit hypotheses were formulated in this regard, since the main focus of this study is on differences in the strength of the influence of certain behavioral determinants between different types of PEBs. Therefore, we restricted our hypotheses to certain differences, which we expected in this latter regard as described in the following. 


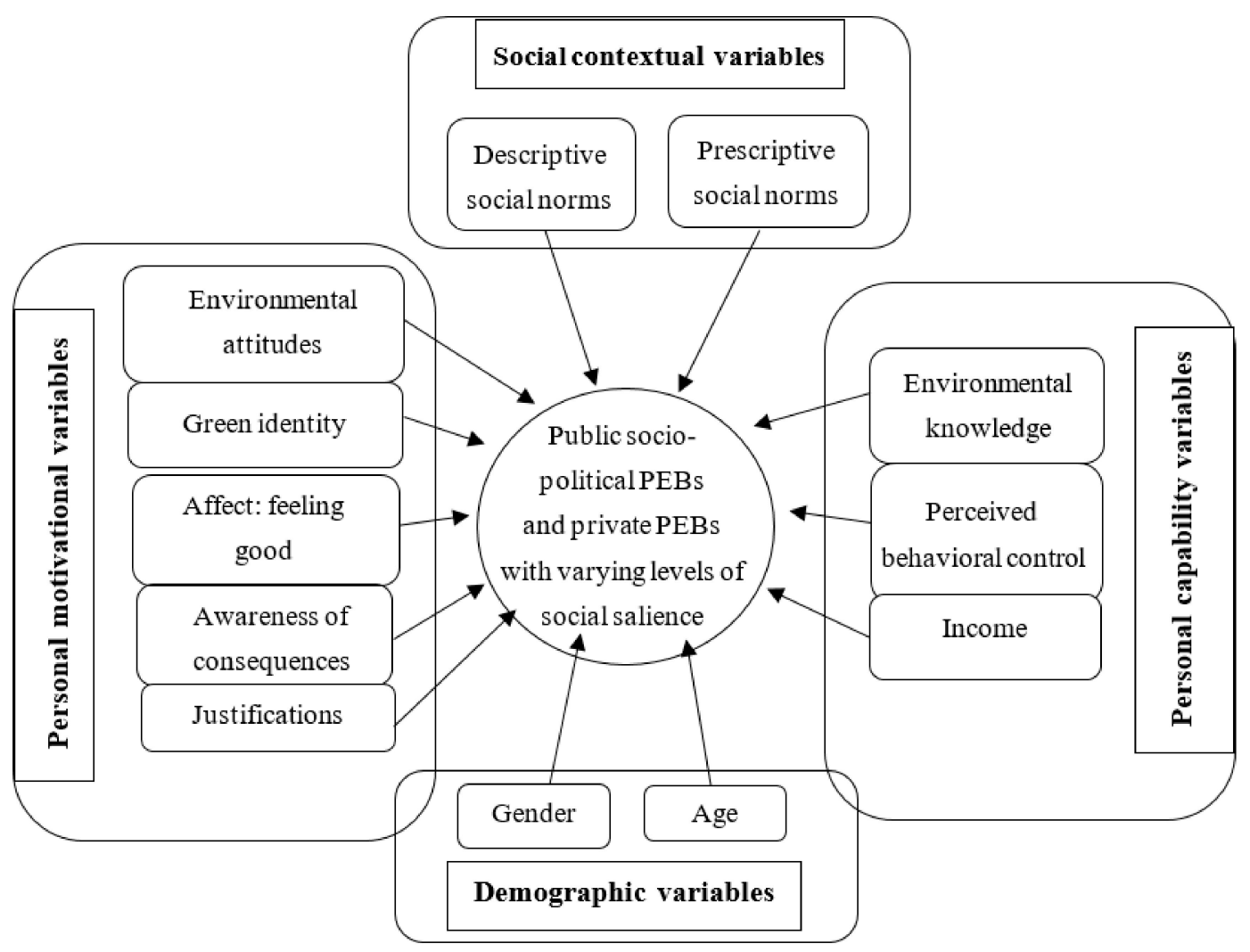

Figure 1. Analytical framework with the predictor variables used for explaining different types of positive environmental behaviors (PEBs) in the present study (Source: original).

\subsubsection{Investigation of Hypotheses on Differences between Determinants of Differenty Types of Pebs}

The differentiation between private sphere behaviors with direct environmental impacts and public sphere behaviors with exclusively indirect socially or politically mediated environmental consequences is the starting point of this study. In this context, a crucial point that Stern [20] did not address is that different degrees of privacy exist among private behaviors with direct impacts on the environment [101]. In fact, one can postulate a continuum of private behaviors. On one pole are socially salient private behaviors that are clearly visible to the social environment, such as the purchasing of a new automobile or the establishment of solar panels on the roof of a self-owned private house, whereas on the other pole are highly discrete private PEBs such as using colder water for showering or laundry and turning on the dish-washer only when it is fully loaded.

Thus, there may be some private PEBs that resemble public sphere PEBs with exclusively socially and politically mediated impacts in so far as they are publicly perceived by the agent's social environment and thereby convey a pro-ecological status and value-related message to others. Such behaviors could be denoted as "lighthouse PEBs" due to their high visibility and communication function as symbolic social self-representations. Similar to public sphere behaviors such as environmental activism, private lighthouse PEBs may exert considerable socially mediated influences on the environment because persons displaying such behaviors may serve as role models motivating others to display similar behaviors [111,112]. This may be true for positive lighthouse PEBs (e.g., establishing solar panels on a roof) as well as environmentally negative lighthouse behaviors (e.g., driving an SUV).

On the background of these considerations and findings of previous research on the drivers of private and public sphere pro-environmental behaviors as described in Section 2.1.5, the five following hypotheses, which are supported by both qualitative, theoretical arguments and previous empirical findings, were formulated. 
Firstly, as explained by Stern [20] and consistent with empirical finding by Stern and colleagues [19], an important role of environmental attitudes and public sphere behaviors such as political pro-environmental behavior or activism may be expected because they are clearly oriented towards ecological ends, whereas specific private sphere PEBs may also be motivated by non-ecological drivers such as financial incentives (e.g., sorting waste reduces disposal costs in private households due to garbage fees, using LED reduces electricity costs, etc.), health and fitness gains (e.g., walking or biking to work instead of driving may bear health benefits), or other non-ecological aspects. Accordingly, Hypothesis 1 was formulated in line with these considerations.

Hypothesis 1. It is expected that pro-environmental attitudes will be a more important determinant of public sphere PEBs compared to private sphere PEBs.

Secondly, social influence factors (i.e., subjective norms within the concept of TPB, descriptive and prescriptive norms according to the focus theory of normative conduct) are expected to be more influential in public sphere behavior where norm-conformity is, in tendency, more observable compared to private sphere behaviors. This assumption is in line with a long tradition and vast amount of studies and literature on social pressure and conformity [92-94,113,114], showing that public behavioral compliance is often stronger than internal acceptance of communicated social behavior norms [115].

It is assumed that this holds for both descriptive and prescriptive social norms, which are considered separately in this research. Therefore, the following Hypotheses 2 and 3 were formulated in this regard.

Hypothesis 2. It is expected that descriptive social norms are more important determinants of public sphere PEBs compared to private sphere PEBs.

Hypothesis 3. It is expected that prescriptive social norms are more important determinants of public sphere PEBs compared to private sphere PEBs.

Previous research has revealed a higher congruency between sustainability-related social norms and corresponding behaviors when there exists social control (e.g., because behaviors are observable and transparent to others) than in situations when behaviors are totally private, non-transparent, and unknown to others [89]. Therefore (and with analogous reasoning as for Hypotheses 2 and 3), it was assumed that social norms are more influential in relation to socially salient and recognizable private sphere behaviors where norm-conformity is observable than for private behaviors that are not socially salient for example because they are obscured from others. Accordingly, the following Hypotheses 4 and 5 were formulated.

Hypothesis 4. It is expected that descriptive social norms are more influential determinants of socially highly salient private (lighthouse) PEBs than of less socially salient private PEBs.

Hypothesis 5. It is expected that prescriptive social norms are more influential determinants of socially highly salient private (lighthouse) PEBs than of less socially salient private PEBs.

These five hypotheses were investigated through the application of a principal component analysis (PCA) to a large set of environmentally significant behaviors including both public and private sphere behaviors and the subsequent application of an encompassing behavioral model aiming to predict distinct behavior types identified by the PCA. This open, partly data-driven procedure allowed for the possibility that in addition to the three types of PEBs (public sphere, lighthouse private sphere, less socially salient private sphere) to which these hypotheses refer, further behavioral types could possibly be identified and explored. The integrative behavior model approach taken in this research also 
represents an explorative means to detect possible further differences between the optimal models for the explanation of different types of PEBs apart from those predicted by the five formulated hypotheses.

\section{Methodologies and Methods}

In this section, the implementation and participants of the survey will be described, followed by the content of the questionnaire and some general rmarks on the statistical analyses that were conducted.

\subsection{Survey Implementation and Participants}

The survey was conducted between 25 October and 19 November 2019. Participants were recruited from a random sample of the resident populations of the German- and French-speaking regions of Switzerland who had internet access and were in the age range of 18-74 years. Individual links for participation in the online survey were sent out via email, and the invited persons had the option to respond to either the German or French version of the online questionnaire. Participation in the survey was voluntary, the anonymity of the surveys was guaranteed, and no financial compensation was paid. The purpose of the study was communicated to the participants in general terms before presentation of the first question.

A total of 1219 persons completed the survey. The average time required to complete the questionnaire was $23.6 \mathrm{~min}$, and only fully completed questionnaires were used in the statistical analyses. Some participants were excluded from the data analyses, as their response time was below the threshold value of six minutes that was defined as a quality requirement for the sincere completion of the questionnaire. As a result, 1206 participants with valid responses were included in the data analysis, including 899 persons who used the German questionnaire and 307 who used the French version. However, the number of interpretable responses varied between the items because many items included the response options "I do not know" or "I do not want to respond to this question," which were considered as missing entries for most analyses.

The gender distribution of the participants was $51.1 \%$ males and $48.9 \%$ females, and the average age of the participants was 47.6 years (median $=49$, mode $=51, \min =18, \max =74, \mathrm{SD}=15.04$ ). Among the participants, $36.6 \%$ were academics possessing at least one university degree (MSc, BSc, diploma) and $63.3 \%$ were non-academics, and $0.2 \%$ (two persons) did not respond to the item addressing education level. The financial situation was assessed as household income for persons living together with their partners or parent(s) and as individual income for other participants. The median household income of the former group ranged from $9000 \mathrm{CHF}$ to 12,000 CHF per month (before taxes), and the median individual income of the remaining persons ranged between $5000 \mathrm{CHF}$ and $7000 \mathrm{CHF}$ per month (1 CHF was nearly equivalent to 1 USD at the time of the survey). However, 164 participants did not disclose their income level.

\subsection{Questionnaire}

\subsubsection{Socio-Demographic and Peb Items}

The questionnaire firstly addressed the socio-demographic variables of gender, age, income, and education level. These items were followed by questions addressing 23 different environmental behaviors, including five public sphere PEBs with mainly socio-politically mediated impacts on the environment (e.g., taking part in a pro-environmental demonstration, donating to a pro-environmental organization, signing a pro-environmental petition). The corresponding items asked how frequently each of the behaviors was performed by the respondent using a six-point scale $(1=$ never, $2=$ very rarely, $3=$ rarely, $4=$ occasionally, $5=$ frequently, $6=$ very frequently). Items that inquired about negative environmental behaviors were reversely coded. The 23 behavior items and the average response values are presented in Table 1. Following the behavior items, personal motivational variables, contextual variables, and personal capability aspects were addressed. 
Table 1. Pro-environmental behavior items.

\begin{tabular}{|c|c|c|c|}
\hline Items & $\mathbf{N}$ & M & SD \\
\hline 1. When I take a holiday, I travel by plane to my holiday destination. ${ }^{a}$ & 1194 & 3.71 & 1.46 \\
\hline $\begin{array}{l}\text { 2. When shopping, I refuse to buy products from companies with a bad reputation } \\
\text { for environmental protection. }\end{array}$ & 1130 & 4.49 & 1.34 \\
\hline 3. When buying food, I prefer to choose ecological (or organic) food options. & 1196 & 4.64 & 1.29 \\
\hline 4. When buying food, I prefer to buy regionally grown fruit and vegetables. & 1198 & 5.34 & 0.85 \\
\hline $\begin{array}{l}\text { 5. I reduce the number of miles I fly by taking the train (or other more } \\
\text { environmentally friendly means of transport) or not travelling at all. }\end{array}$ & 1118 & 4.13 & 1.69 \\
\hline 6. I leave the dishwasher running when it is almost empty or only about half full. ${ }^{a}$ & 1160 & 5.38 & 1.07 \\
\hline 7. I use a tumble dryer instead of a clothesline when drying wet clothes. ${ }^{a}$ & 1188 & 4.01 & 1.73 \\
\hline 8. I wash my clothes at $30^{\circ} \mathrm{C}$ or in cold water. & 1159 & 3.95 & 1.51 \\
\hline 9. Instead of turning up the heat in winter, I wear warm clothes. & 1186 & 4.50 & 1.34 \\
\hline 10. I take a long hot shower (more than five minutes). ${ }^{a}$ & 1201 & 3.98 & 1.51 \\
\hline 11. I unplug or switch off my electronic devices when I am not using them & 1203 & 4.36 & 1.56 \\
\hline 12. I throw away food at home when it gets too old or goes bad. ${ }^{\text {a }}$ & 1201 & 4.18 & 1.25 \\
\hline 13. I sort my waste for recycling. & 1204 & 5.78 & 0.58 \\
\hline 14. I repair things instead of buying new ones. & 1195 & 4.65 & 1.01 \\
\hline 15. I buy second-hand items or used products instead of new ones. & 1197 & 3.25 & 1.42 \\
\hline 16. I leave the light on in rooms of my apartment even when it is not needed. ${ }^{a}$ & 1205 & 5.06 & 1.11 \\
\hline 17. I collect smaller waste when I see it lying outside in nature or in public places. & 1200 & 3.85 & 1.32 \\
\hline $\begin{array}{l}\text { 18. I simply throw smaller rubbish on the ground or leave it behind on the way } \\
\text { instead of disposing of it correctly. }{ }^{\text {a }}\end{array}$ & 1204 & 5.78 & 0.75 \\
\hline 19. I have participated in peaceful demonstrations for the environment & 1195 & 1.48 & 1.05 \\
\hline $\begin{array}{l}\text { 20. I have made a donation to an environmental organization or environmental } \\
\text { project or request }\end{array}$ & 1183 & 2.89 & 1.70 \\
\hline 21. I have worked or volunteered for an environmentally friendly organization. & 1187 & 1.51 & 1.17 \\
\hline 22. I have convinced others to behave in a more environmentally friendly manner. & 1148 & 3.66 & 1.39 \\
\hline 23. I have signed a petition for an environmental issue or cause. & 1145 & 2.92 & 1.77 \\
\hline
\end{tabular}

All items used a six-point Likert scale $(1=$ never, $2=$ very rarely, $3=$ rarely, $4=$ occasionally, $5=$ frequently, 6 = very frequently). Responses of the category "not applicable" or "I do not know" were excluded, such that numbers of valid responses from the overall 1206 participants varied from $n=1350$ to 1853 between the items. ${ }^{a}$ For these negative environmental behaviors, the scale was reversed to enable their possible inclusion in PEB scales. Reported means (M) for these items show the corresponding reversely-poled scaling whereby high values represent frequent PEBs.

\subsubsection{Personal Motivational Variables}

General environmental attitudes were assessed using a set of five items from an existing scale developed by Diekmann [116,117], which were complemented by an additional item assessing participants' agreement with the statement "the protection of the environment is very important to me." The six items measured agreement ratings on a four-point response scale $(1=$ do not agree at all, 2 = rather disagree, 3 = rather agree, $4=$ I fully agree) and are listed in Table 2 together with average responses and results of a corresponding Cronbach's alpha scale reliability analysis.

Various further personal motivational factors were measured with single items and are listed in Table 3. Among these, green identity was measured using one item assessing agreement with the statement "I am an environmentally conscious consumer." The positive affect connected with PEBs (feeling good) was addressed by an item measuring agreement with the statement "I feel good when behaving in an environmentally friendly way." Awareness of consequences was assessed by an item assessing participants' agreement with the statement "I believe that my personal behavior can bring about a (positive) environmental change.". 
Table 2. Items addressing general environmental attitudes and Cronbach's alpha scale analysis.

\begin{tabular}{|c|c|c|c|c|c|}
\hline General Environmental Attitudes Scale & $\mathbf{N}$ & $\mathbf{M}$ & SD & r (Item Scale) & $\alpha$ (If Item Deleted) \\
\hline $\begin{array}{l}\text { 1. If we continue as we have been doing, we are } \\
\text { heading for an environmental disaster. }\end{array}$ & 1127 & 3.24 & 0.83 & 0.67 & 0.74 \\
\hline $\begin{array}{l}\text { 2. In my opinion, many environmentalists greatly } \\
\text { exaggerate the importance of the } \\
\text { environmental problem. }{ }^{\text {a }}\end{array}$ & 1129 & 2.97 & 1.00 & 0.61 & 0.76 \\
\hline $\begin{array}{l}\text { 3. For the sake of the environment, we should all be } \\
\text { prepared to reduce our current standard of living. }\end{array}$ & 1164 & 3.01 & 0.85 & 0.57 & 0.77 \\
\hline $\begin{array}{l}\text { 4. Environmental protection measures should be } \\
\text { enforced even if they result in job losses. }\end{array}$ & 1066 & 2.64 & 0.89 & 0.55 & 0.77 \\
\hline $\begin{array}{l}\text { 5. It is still the case that politicians do far too little for } \\
\text { the environment. }\end{array}$ & 1146 & 3.13 & 0.88 & 0.50 & 0.78 \\
\hline $\begin{array}{l}\text { 6. The protection of the environment is very } \\
\text { important to me. }\end{array}$ & 1191 & 3.49 & 0.59 & 0.46 & 0.79 \\
\hline Cronbach alpha (additive raw scale, missing listwise) & 966 & 18.64 & 3.62 & $\alpha=$ & 0.80 \\
\hline $\begin{array}{c}\text { Final scale values (items averaged, missing } \\
\text { values estimated) }\end{array}$ & 1206 & 3.08 & 0.57 & & \\
\hline
\end{tabular}

All items used a four-point Likert scale (1 = do not agree at all, 2 = rather disagree, $3=$ rather agree, $4=$ I fully agree). Responses in the category "I do not want to respond" or "I do not know" were treated as missing values. Item-to-scale correlations have been corrected by excluding the item itself from the scale value. The total scale value for each participant was calculated as the average rating of the six items, with missing values being estimated by the overall mean values of each item. ${ }^{\text {a }}$ For this statement, the response scale coding was reversed to allow for inclusion in the General Environmental Attitude scale. Reported means (M) for these items evince reversely poled scaling whereby high values represent positive environmental attitudes.

Table 3. Descriptive statistics for personal motivational variables, social norms, and psychological capability variables measured by single items or two items.

\begin{tabular}{|c|c|c|c|}
\hline & $\mathbf{N}$ & $\mathbf{M}$ & SD \\
\hline \multicolumn{4}{|l|}{ Personal motivational variables } \\
\hline \multicolumn{4}{|l|}{ Green identity } \\
\hline "I am an environmentally conscious consumer." & 1174 & 3.24 & 0.62 \\
\hline \multicolumn{4}{|l|}{ Affect, feeling good } \\
\hline "I feel good when behaving in an environmentally friendly way." & 1142 & 3.40 & 0.69 \\
\hline \multicolumn{4}{|l|}{ Awareness of consequences } \\
\hline $\begin{array}{l}\text { "I believe that my personal behavior can bring about a (positive) } \\
\text { environmental change." }\end{array}$ & 1121 & 3.03 & 0.80 \\
\hline \multicolumn{4}{|l|}{ Social contextual variables } \\
\hline \multicolumn{4}{|l|}{ Descriptive social norm } \\
\hline $\begin{array}{l}\text { "People who are important to me usually behave in an environmentally } \\
\text { friendly way." }\end{array}$ & 1076 & 3.00 & 0.62 \\
\hline \multicolumn{4}{|l|}{ Prescriptive social norm } \\
\hline $\begin{array}{l}\text { "In general, the people close to me expect me to behave in an environmentally } \\
\text { friendly manner." }\end{array}$ & 1038 & 2.95 & 0.82 \\
\hline \multicolumn{4}{|l|}{ Psychological capability variables } \\
\hline \multicolumn{4}{|l|}{ Self-evaluated knowledge } \\
\hline $\begin{array}{l}\text { How do you rate your level of knowledge on environmental issues and } \\
\text { environmental protection compared to the average Swiss population? }\end{array}$ & 1190 & 3.49 & 0.77 \\
\hline \multicolumn{4}{|l|}{ Perceived behavioral control } \\
\hline "I can easily behave in an environmentally friendly manner if I want to." & 1162 & 3.24 & 0.75 \\
\hline "It is very easy for someone like me to be environmentally friendly." & 1163 & 3.13 & 0.71 \\
\hline
\end{tabular}

All items (except for ${ }^{a}$, see below) were answered on a four-point Likert scale $(1=$ do not agree at all, $2=$ rather disagree, 3 = rather agree, 4 = I fully agree). Responses of the category "I do not want to respond" or "I do not know" were excluded. ${ }^{a}$ Five-point response scale from clearly below average to clearly above average $(1=$ clearly below average, 2 = rather below average, 3 = average, $4=$ rather above average $5=$ clearly above average). 
Justifications were assessed by measuring levels of agreement with four statements, including "there are more important things in life than protecting the environment, so polluting the environment is justified to a certain extent." The four items were incorporated as a brief justifications for negative behaviors scale (see Table 4 for the individual items and the reliability analysis).

Table 4. Items addressing justifications and Cronbach's alpha scale analysis.

\begin{tabular}{|c|c|c|c|c|c|}
\hline Justification Scale Items & $\mathbf{N}$ & $\mathbf{M}$ & SD & r (Item Scale) & $\alpha$ (If Item Deleted) \\
\hline $\begin{array}{l}\text { 1. There are more important things in life than } \\
\text { protecting the environment, so polluting the } \\
\text { environment is justified to a certain extent. }\end{array}$ & 1164 & 1.56 & 0.78 & 0.45 & 0.61 \\
\hline $\begin{array}{l}\text { 2. The impact of a single person's environmental } \\
\text { behavior is small, so it is not worth limiting oneself } \\
\text { for the environment. }\end{array}$ & 1169 & 1.59 & 0.80 & 0.43 & 0.62 \\
\hline $\begin{array}{l}\text { 3. I behave very environmentally friendly in most } \\
\text { areas of life, so it is okay if some of my behaviors } \\
\text { pollute the environment (e.g., go on holiday now } \\
\text { and then). }\end{array}$ & 1128 & 2.43 & 0.88 & 0.41 & 0.64 \\
\hline $\begin{array}{l}\text { 4. Environmentally friendly behavior is often more } \\
\text { expensive than environmentally unfriendly behavior, } \\
\text { so it is okay if some of my behaviors pollute the } \\
\text { environment (e.g., flying to a holiday destination } \\
\text { now and then instead of travelling more expensively } \\
\text { by train). }\end{array}$ & 1120 & 2.06 & 0.90 & 0.53 & 0.55 \\
\hline Cronbach alpha (missing listwise) & 1044 & 7.58 & 2.38 & $\alpha=$ & 0.67 \\
\hline $\begin{array}{l}\text { Final scale values (items averaged, missing } \\
\text { values estimated) }\end{array}$ & 1206 & 1.91 & 0.58 & & \\
\hline
\end{tabular}

All items were assessed on a four-point Likert scale $(1=$ do not agree at all, 2 = rather disagree, $3=$ rather agree, $4=\mathrm{I}$ fully agree). Responses of the category "I do not want to respond" or "I do not know" were excluded. Item-to-scale correlations were corrected by excluding items from the scale value. The total scale value for each participant was calculated as the average rating of the six items, with missing values being estimated by the overall mean values of each item.

\subsubsection{Contextual Forces: Descriptive and Prescriptive Social Norms}

To measure social contextual forces, descriptive social norms were addressed by soliciting levels of agreement with the statement "People who are important to me usually behave in an environmentally friendly way" and prescriptive social norms were assessed using the item "In general, the people close to me expect me to behave in an environmentally friendly manner" (Table 3).

\subsubsection{Psychological Capability Factors and Further Items}

As capability factors, self-evaluated knowledge about environmental problems was assessed with one item, and perceived behavioral control to display PEBs was measured with the two items "I can easily behave in an environmentally friendly manner if I want to" and "It is very easy for someone like me to be environmentally friendly" (Table 3).

In addition to these questions, the survey contained some further items related to political and environmental topics that are not addressed in this study.

\subsection{Statistical Analysis}

The statistical analyses were performed using IBM SPSS Version 25 for Macintosh systems. To avoid an accumulation of missing cases in multivariate analyses involving scales, missing values caused by the selection of supplementary response options such as "I do not know" or "I do not want to respond" were estimated by the overall mean of the respective variable in the total dataset, which is a common approach with conservative effects on correlations between variables. As a central analysis, a PCA was conducted on the 23 PEB items. Based on the resulting component loadings, the PEB items were assigned to different groups, and Cronbach's alpha analyses were conducted to 
validate corresponding behavioral scales. The resulting scales were then investigated by means of a repeated measures ANOVA using the variables of an encompassing environmental behavior model as between-subject factors and the different types of behaviors (represented by scales) as within-subject factors. This enabled the computation of prediction models for each type of PEB based on a general set of predictors and the investigation of significant differences between these prediction models as interaction effects (environmental behavior model predictor $X$ type of PEB).

\section{Results}

Descriptive statistics of, firstly, the PEB items and, secondly, of the variables representing possible determinants of environmentally significant behavior are reported. Then, the findings of a PCA conducted to distinguish between different types of PEBs are presented. Finally, a repeated measures ANOVA representing an integrative environmental behavior model is applied to explain distinct types of private and public PEBs.

\subsection{Descriptive Statistics of Pebs}

Table 1 displays the average values of the frequency ratings of the 23 environmental behaviors measured in this study. The most common PEBs were to sort waste for recycling and (reversely coded) not to litter waste, both of which obtained the same maximum average value of $M=5.8$, which was quite close to the scale maximum of 6 (="very often"). In contrast, the two rarest PEBs, each of which obtained a mean value of 1.5 (i.e., in the middle between "never" and "very rarely"), were participation in peaceful demonstrations for the environment and working or volunteering for an environmentally friendly organization.

\subsection{Predictors of the Environmental Behavior Model}

The average agreement ratings for the items addressing environmental attitudes are listed in Table 2 along with the results of the reliability analysis. All six item-to-scale correlations were larger than $r=0.45$, which reflects an acceptable level of consistency. The scale's overall Cronbach's alpha value was acceptable at $\alpha=0.8$. All items were retained in the scale, as omitting any items would have reduced the overall Cronbach's alpha value (see last column in Table 2).

Table 3 presents the average ratings for the single items representing psychological constructs. In addition, the correlation between prescriptive and descriptive norms was calculated, which proved to be significant with $\mathrm{r}=0.45(p<0.001)$. Nonetheless, based on the above-elucidated theoretical grounds, this correlation seemed small enough to treat the two types of norms as two separate predictor variables in the encompassing behavior model.

The correlation between the two perceived behavioral control items "I can easily be environmentally friendly if I want to" and "It is very easy for someone like me to be environmentally friendly" was likewise calculated and proved to be significant with $r=0.52(p<0.001)$. Since both items were presumed to measure the same construct, an average value of both variables was considered appropriate to serve as the PBC measure in the encompassing environmental behavior model.

The participants' average ratings in the four justification items are shown in Table 4 along with the results of a corresponding Cronbach's alpha analysis. The overall $\alpha$ of 0.67 was acceptable, and the same was true for the corrected item scale correlations, which consistently exceeded 0.4. All items were kept in the scale, as omitting any item would have reduced the overall Cronbach's alpha value. Among the four justifications, the statement "I behave very environmentally friendly in most areas of life, so it is also okay if some of my behaviors pollute the environment" obtained the highest score with $\mathrm{M}=2.4$, which roughly corresponds to a neutral rating between rather disagree $(\approx 2)$ and rather agree $(\approx 3)$. 


\subsection{Pca Results}

A PCA was conducted on the 23 PEB items to investigate their factorial structure and identify factors that are able to account for common variance of certain (types of) behaviors. The scree plot was interpreted in order to determine the number of components to be extracted (Figure 2). The upward bent in the plot from components 3 to 2 suggested the extraction of two principle components with initial eigenvalues of $L_{1}=4.86$ and $L_{2}=1.98$. The graphical scree-test was preferred to the Kaiser Gutman criterion because the latter tends to lead to the extraction of rather too many factors if the number of variables is quite large [118].

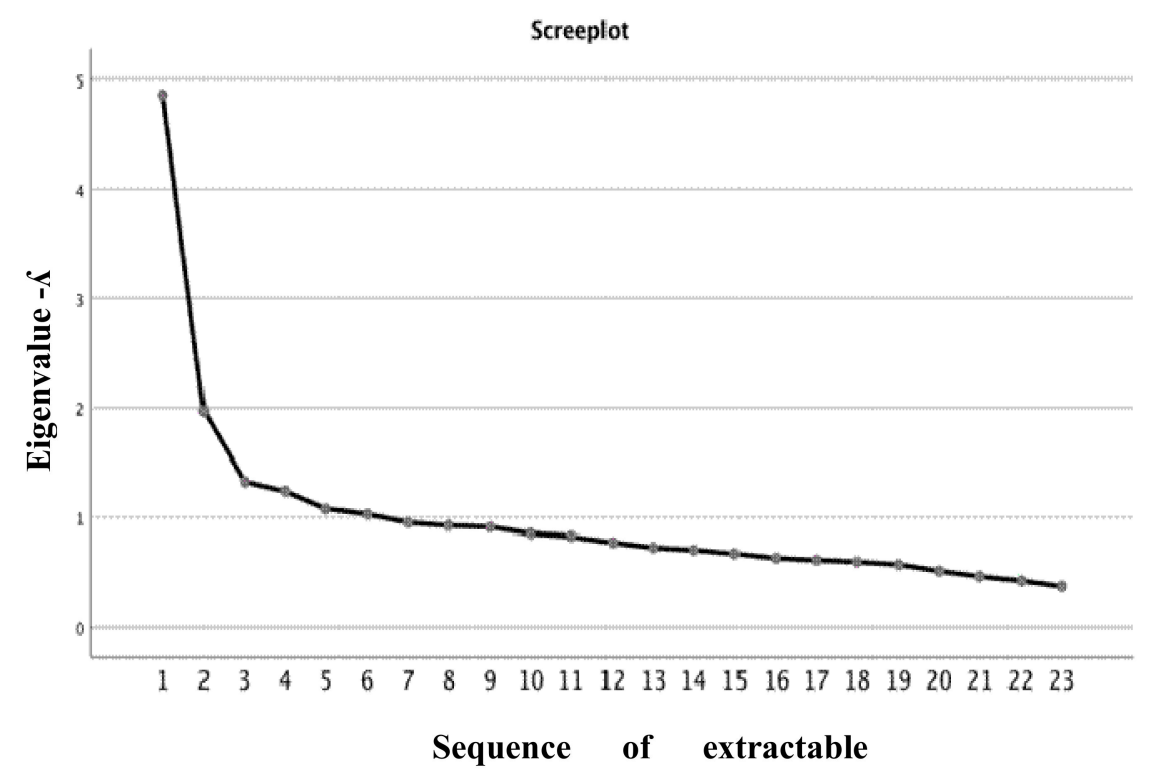

Figure 2. Screeplot with eigenvalues $L$ of sequentially extractable factors (components) of the PCA of the 23 PEBs (Source: original).

The resulting initial factor-loading matrix was rotated based on the Varimax criterion to arrive at a clearer factorial structure. The resulting rotated components possessed eigenvalues of $L_{1}=4.02$ and $L_{2}=2.82$. Table 5 presents the corresponding rotated component loading matrix with the loadings of the different PEBs on the two extracted and rotated factors.

According to Guadagnoli and Velicer [119], variables with component loadings of 0.30 or 0.40 are usually regarded as salient for the corresponding component, whereas loadings with smaller absolute values are ignored. A threshold of $\mathrm{a}=0.35$, which is the mid-point of these two values, was accordingly defined in this study as the criterion for a behavior item to form part of a certain component and thus be assigned to a corresponding behavioral scale. However, if an item loaded higher than 0.35 on both extracted components, it was assigned to the scale of the component on which it loaded highest, as this component was then assumed to best reflect the respective behavior item. Two items showed small loadings below 0.35 on both components and were therefore omitted from the subsequent analyses. 
Table 5. Rotated factor-loading matrix of the PCA of the environmental behavior items.

\begin{tabular}{|c|c|c|c|}
\hline & \multicolumn{2}{|c|}{ Component } & \multirow{2}{*}{ Assigned Scale } \\
\hline & 1 & 2 & \\
\hline 1. When I take a holiday, I travel by plane to my holiday destination. ${ }^{a}$ & 0.24 & 0.42 & private \\
\hline $\begin{array}{l}\text { 2. When shopping, I refuse to buy products from companies with a } \\
\text { bad reputation for environmental protection. }\end{array}$ & 0.56 & 0.39 & lighthouse \\
\hline $\begin{array}{l}\text { 3. When buying food, I prefer to choose ecological (or organic) } \\
\text { food options. }\end{array}$ & 0.55 & 0.26 & lighthouse \\
\hline $\begin{array}{l}\text { 4. When buying food, I prefer to buy regionally grown fruit } \\
\text { and vegetables. }\end{array}$ & 0.35 & 0.44 & private \\
\hline $\begin{array}{l}\text { 5. I reduce the number of miles I fly by taking the train (or other more } \\
\text { environmentally friendly means of transport) or not travelling at all. }\end{array}$ & 0.51 & 0.37 & lighthouse \\
\hline $\begin{array}{l}\text { 6. I leave the dishwasher running when it is almost empty or only } \\
\text { about half full. a }\end{array}$ & -0.04 & 0.46 & private \\
\hline $\begin{array}{l}\text { 7. I use a tumble dryer instead of a clothesline when drying } \\
\text { wet clothes. }{ }^{\text {a }}\end{array}$ & 0.14 & 0.31 & none \\
\hline 8. I wash my clothes at $30^{\circ} \mathrm{C}$ or in cold water. & 0.27 & 0.18 & none \\
\hline 9. Instead of turning up the heating in winter, I wear warm clothes. & 0.36 & 0.41 & private \\
\hline 10. I take a long hot shower (more than five minutes). ${ }^{a}$ & 0.05 & 0.51 & private \\
\hline $\begin{array}{l}\text { 11. I unplug or switch off my electronic devices when I am not } \\
\text { using them }\end{array}$ & 0.34 & 0.40 & private \\
\hline 12. I throw away food at home when it gets too old or goes bad. ${ }^{a}$ & 0.00 & 0.50 & private \\
\hline 13. I sort my waste for recycling. & 0.14 & 0.40 & private \\
\hline 14. I repair things instead of buying new ones. & 0.29 & 0.35 & private \\
\hline $\begin{array}{l}\text { 15. I buy second-hand items or used products instead of buying } \\
\text { new ones. }\end{array}$ & 0.51 & 0.04 & lighthouse \\
\hline $\begin{array}{l}\text { 16. I leave the light on in rooms of my apartment even when it is } \\
\text { not needed. a }\end{array}$ & 0.02 & 0.56 & private \\
\hline $\begin{array}{l}\text { 17. I collect smaller waste when I see it lying outside in nature or in } \\
\text { public places. }\end{array}$ & 0.40 & 0.13 & lighthouse \\
\hline $\begin{array}{l}\text { 18. I simply throw smaller rubbish on the ground or leave it behind } \\
\text { on the way instead of disposing of it correctly. }{ }^{\text {a }}\end{array}$ & -0.13 & 0.41 & private \\
\hline $\begin{array}{l}\text { 19. I have participated in peaceful demonstrations for } \\
\text { the environment }\end{array}$ & $\underline{0.64}$ & -0.23 & publicc \\
\hline $\begin{array}{l}\text { 20. I have made a donation to an environmental organization or } \\
\text { environmental project or request }\end{array}$ & $\underline{0.68}$ & 0.05 & public \\
\hline $\begin{array}{l}\text { 21. I have worked or volunteered for an environmentally } \\
\text { friendly organization. }\end{array}$ & $\underline{0.56}$ & -0.17 & public \\
\hline $\begin{array}{l}\text { 22. I have convinced others to behave in a more environmentally } \\
\text { friendly manner. }\end{array}$ & $\underline{0.59}$ & 0.21 & public \\
\hline 23. I have signed a petition for an environmental issue or cause. & $\underline{0.76}$ & 0.04 & public \\
\hline
\end{tabular}

The Varimax rotation method was applied. Loadings on components to which an item (behavior) was assigned are printed in bold. In addition loadings of public sphere PEBs on Component 1 are underscored $(\mathrm{N}=1206$; occasional missing values for the PEBs were estimated by the grand mean of the respective behavior).

Accordingly, the five public sphere behaviors all loaded considerably high on component 1 (Table 5, behavior items 19-23, loadings between $\mathrm{a}=0.56$ and $\mathrm{a}=0.76$ ). In addition, there were some private sphere behaviors that loaded considerably on this component, namely items 2, 3, 5, 15 , and 17 , for which loadings ranged between 0.40 and 0.56 . Although these two sets of behaviors loaded on the same factorial component, they represent different types of environmental behaviors; as defined by Stern [20], public sphere behaviors influence the environment indirectly via social and political influence, whereas private sphere PEBs have a straightforward, direct positive impact on the environment. Furthermore, there were some private sphere behaviors that loaded considerably on 
component 2, namely items $1,4,6,9$ to 14,16 , and 18 , for which loadings ranged between 0.35 and 0.56. Accordingly, it was decided to use these three sets of items as the basis for the construction of three different PEB scales that were presumed to represent different types of PEBs: (1) public sphere behaviors with socio-political primary goals that are instrumental indirectly for ecological aims as secondary goals [20]; (2) lighthouse private sphere behaviors; and (3) less socially salient private sphere behaviors. Thus, in addition to a separation of public sphere PEBs from private PEBs, two different types of private PEBs were derived from the PCA loading pattern (Table 5). The term lighthouse PEBs seemed appropriate for the private sphere PEBs loading on component 1 for two reasons. Firstly, public sphere behaviors also loaded highly on component 1 , which suggested some similarity of these private sphere behaviors to public sphere behaviors, thereby implying a high public visibility (social salience) of these behaviors. Secondly, when analyzing the content of these behaviors, it was recognized that they tend to involve the communication of an ecologically oriented message promoting sustainability-related values to others. Together, these two aspects-high visibility and communication function-raised the association to a lighthouse.

Some examples of lighthouse private sphere and less socially salient behaviors shall briefly illustrate this reasoning:

To refuse to buy products from companies with a bad reputation for environmental protection (behavior item 2, lighthouse private PEB) seems to include a strong sustainability-oriented message to others. The same is true for behavior item 5, "I reduce the number of miles I fly by taking the train (or other more environmentally friendly means of transport) or not travelling at all." Similarly, if someone cleans up the environment, this may be well visible to others and sends a public message that keeping the environment clean is important (behavior item 17, lighthouse private PEB). On the contrary, littering waste often occurs when social control is lacking, and people tend to try to hide this misconduct from others. Hence, although previous research has shown that social norms influence littering behavior $[41,43,82,83]$, the corresponding social influence may be weakened if it is socially non-transparent and unobserved and thus unknown to others whether a person litters (behavior item 18, non-lighthouse private PEB). Such a non-transparency seems even more emphasized for at-home behaviors such as running the dishwasher when it is nearly empty or only about half full (behavior item 6) or taking very long hot showers (behavior item 10), which do not seem to be socially salient and are obscured from others and therefore represent non-lighthouse private PEBs.

A Cronbach's alpha reliability analysis was performed for the three resulting scales. When considering the five public sphere behaviors as a scale, the resulting Cronbach's alpha value was 0.73 . The Cronbach's alpha of the items representing the 5 lighthouse PEBs and 11 non-lighthouse private PEBs were 0.63 and 0.67 , respectively. Deleting any items from any of these three scales would have reduced their respective Cronbach's alpha value. Therefore, no items were omitted, and the average ratings for the 5 public sphere, 5 lighthouse, and 11 less socially salient private behavior items where considered as measures of how frequently each participant engaged in each of the three types of PEB.

\subsection{Repeated Measures Anova Representing the Behavior Model}

To investigate the roles of different predictors derived from previous research on PEBs in influencing the three types of PEB distinguished on basis of the PCA, a repeated measures ANOVA was conducted with PEB type as the within-subject factor (three levels encompassing public sphere, lighthouse private sphere, non-lighthouse private sphere PEBs). This method was deemed to be most appropriate because it calculates separate prediction models (parameter estimates) and significance tests for each PEB type and additionally enables testing for significant differences in the roles that certain predictors play in influencing the three different types of behaviors. Such differences are captured as interaction effects between the between-subject factor predictor variables and the within-subject factor PEB type. 
The between-subject predictor variables of the model included personal motivational determinants such as (i) general environmental attitudes, (ii) green self-identity, (iii) positive affect (feeling good), (iv) awareness of consequences, and (v) justifications, as well as contextual social forces represented by (vi) prescriptive and (vii) descriptive social norms, and personal capabilities, namely, (viii) environmental knowledge, (ix) education level, (x) perceived behavioral control, (xi) income, and finally, the demographic control variables (xii) gender and (xiii) age. All predictors were entered as covariates into the general linear ANOVA model. The dependent measure and the psychological predictor variables were represented by the scales described in Section 4.2. Gender was represented by a two-level variable (coded $1=$ male, $2=$ female) and the same was true for education level $(0=$ no academic degree, $1=$ with academic degree). The two cases with missing values for the latter variable were randomly assigned to a category. Income was represented by a three-level variable $(0=$ income below the median category, $1=$ income within the median category, $2=$ income above the median category). For the 164 non-respondents, the median category was used as the statistically most neutral income estimate. Because income effects are not at the foreground of the present study, this procedure was deemed the best means to avoid losing the information these participants provided in relation to all of the other predictor variables.

Collinearity measures for the 13 predictors revealed no corresponding problems; however, the Mauchley test of sphericity revealed a significant violation of the homogeneity of covariance between the three repeated measures of the within-subject factor $\left(\chi^{2}=74.97, \mathrm{df}=2, p<0.001\right)$. A corresponding epsilon correction (Huynh-Feldt $\varepsilon=0.94$ ) of the degrees of freedom of the F-distribution used to calculate the significances for the within-subject factors and corresponding interaction effects was conducted to take this into account.

The analyses revealed a significant main effect of the within-subject factor PEB type $(p<0.001)$. Public sphere behaviors $(M=2.5)$ were significantly less frequently displayed than lighthouse sphere behaviors $(M=4.1)$; however, less socially salient private sphere behaviors $(M=4.8)$ were most frequently evinced.

The tests of between-subject factors (Table 6) show which variables of the behavioral model significantly contribute to the explanation of PEBs in general (i.e., when averaging the three PEB types for each participant). Accordingly, general environmental attitudes and (self-evaluated) environmental knowledge were the strongest predictors (for both: partial eta squared $\eta^{2}=0.087, p<0.001$ ) of PEBs, followed by green identity, justifications, awareness of consequences, gender, and prescriptive social norms (for all five predictors, $p \leq 0.001$ and $\left.\eta^{2} \geq 0.009\right)$, age $(p<0.01)$, and perceived behavioral control $\left(p<0.05, \eta^{2}=0.005\right)$, respectively.

Differences in the importance of predictors for explaining the three different types of PEB were tested within the repeated measures ANOVA through interaction effects between the within-subject factors (type of $\mathrm{PEB}$ ) and between-subject factors (predictor variables of the behavioral model), as shown in Table 7. The analysis revealed significant interactions between PEB type and predictors for seven predictor variables. The strongest effect size was observed for general environmental attitudes $\mathrm{X}$ PEB type $\left(\eta^{2}=0.029, p<0.001\right)$, which were significantly more important for the public sphere $(b=0.52)$ and lighthouse private PEBs $(b=0.40)$ than for non-lighthouse private PEBs $(b=0.07 ; p<0.001$ in both comparisons). The simple contrast between the influence of general environmental attitudes for public sphere and private lighthouse PEBs was likewise significant $(p<0.05)$, which confirmed Hypothesis 1 that general environmental attitudes are particularly important in influencing public sphere behaviors. In addition, environmental attitudes proved more important for private lighthouse than less socially salient private PEBs.

A weaker interaction effect in the opposite direction was observed for green identity $\left(\eta^{2}=0.004\right.$, $p<0.05$ ), which was in fact most strongly related to non-lighthouse private behaviors, followed by lighthouse private PEBs, and least strongly related to public sphere behaviors. Contrasts for the interaction effect showed significant differences in the b-weights of green identity for both lighthouse $(p<0.05)$ and non-lighthouse private PEBs $(p<0.01)$ compared with public sphere PEBs. 
We also found a significant interaction effect $\left(\eta^{2}=0.024, p<0.001\right)$ between PEB type and environmental knowledge, the latter of which proved more important for the prediction of public sphere behaviors $(b=0.34)$ compared with lighthouse $(b=0.19)$ and non-lighthouse private PEBs $(b=0.08)$. A weaker $\left(\eta^{2}=0.005, p<0.01\right)$ but somewhat parallel interaction effect was found for education level, which was positively and significantly related to public sphere behaviors $(p<0.05)$ but unrelated to lighthouse private behaviors and even significantly $(p<0.05)$ negatively related to non-lighthouse private PEBs (see Table 7).

A highly significant interaction effect was revealed for prescriptive social norms $\left(\eta^{2}=0.006\right.$, $p<0.001)$, which were found to be a significant predictor for public sphere PEBs $\left(b=0.145, \eta^{2}=0.01\right.$, $p<0.001$ ) but not for the two types of private behaviors. This finding clearly confirms Hypothesis 3 regarding a strong influence of social norms in the public sphere but implies the rejection of Hypotheses 5 , which assumed a similar difference between private lighthouse and non-lighthouse PEBs with respect to the influence of social norms. However, descriptively, the smallest b-weight of prescriptive norms was indeed observed for less socially salient non-lighthouse PEB $(b=0.005)$.

The Hypotheses 2 and 4 had to rejected as there was no significant influence of descriptive social norms on any of the three types of PEBs.

A significant interaction effect was also observed for age $\left(\eta^{2}=0.008, p<0.001\right)$ which proved to be significantly and strongly positively related to non-lighthouse private PEBs $\left(\eta^{2}=0.042, p<0.001\right)$ but unrelated to public sphere and lighthouse private behaviors. This latter finding was only partially consistent with bivariate correlations between age and the three types of PEBs that were additionally calculated. These bivariate correlations did not prove significant for the public sphere PEBs $(r=0.03$, $p=0.272$ ), showed a very small but significant positive correlation between age and lighthouse private PEBs $(r=0.08, p<0.01)$ and revealed a more substantial and highly significant positive correlation between age and non-lighthouse private PEBS $(r=0.27, p<0.001)$. The seeming inconsistency between a small but significant bivariate correlation between age and lighthouse private PEBs and a non-significant b-weight of age in the regression model for the lighthouse PEBs is not unusual, however, because manifold predictor variables contribute to the explanation of variance in the regression model and therefore can make the variable age redundant there.

Table 6. Test of the between-subject factors and covariates of the repeated measures ANOVA with PEB type (three levels: public, lighthouse private, non-lighthouse private) as a within-subject factor showing which predictors contribute to the explanation of PEBs when aggregating over the three PEB types.

\begin{tabular}{|c|c|c|c|c|c|c|}
\hline Between-Subjects Source of Variance & SS & Df & MS & $\mathbf{F}$ & Sig. & Partial Eta-Squared $\eta^{2}$ \\
\hline General environmental attitudes & 23.19 & 1 & 23.19 & 114.16 & $0.000 * * *$ & 0.087 \\
\hline Green identity & 9.87 & 1 & 9.87 & 48.60 & $0.000 * * *$ & 0.039 \\
\hline Positive affect, feeling good & 0.52 & 1 & 0.52 & 2.54 & 0.111 & 0.002 \\
\hline Awareness of consequences & 2.85 & 1 & 2.85 & 14.01 & $0.000 * * *$ & 00.012 \\
\hline Justifications & 8.89 & 1 & 8.89 & 43.76 & $0.000 * * *$ & 0.035 \\
\hline Prescriptive social norms & 2.21 & 1 & 2.21 & 10.86 & $0.001 * *$ & 0.009 \\
\hline Descriptive social norms & 0.23 & 1 & 0.23 & 1.14 & 0.285 & 0.001 \\
\hline Environmental knowledge & 22.95 & 1 & 22.95 & 112.97 & $0.000 * * *$ & 0.087 \\
\hline Education level & 0.07 & 1 & 0.07 & 0.33 & 00.565 & 0.000 \\
\hline Perceived behavioral control & 1.11 & 1 & 1.11 & 5.48 & $0.019 *$ & 0.005 \\
\hline Age & 1.61 & 1 & 1.61 & 7.90 & $0.005^{* *}$ & 0.007 \\
\hline Gender & 2.80 & 1 & 2.80 & 13.78 & $0.000 * * *$ & 0.011 \\
\hline Income & 0.54 & 1 & 0.54 & 2.66 & 0.104 & 0.002 \\
\hline Error & 242.14 & 1192 & 0.20 & & & \\
\hline
\end{tabular}


Table 7. Parameter estimates (b-weights), effect sizes, and significance values of the model variables for the prediction the three types of PEBs (public, lighthouse private, non-lighthouse private) and significance values of the interaction effects of within-subject factors $X$ between-subject factors of the repeated measures ANOVA.

\begin{tabular}{|c|c|c|c|c|c|c|c|}
\hline \multirow{2}{*}{$\begin{array}{l}\text { Source of Variance: Predictors and } \\
\text { Interaction Effects Predictors X PEB Types }\end{array}$} & \multicolumn{2}{|c|}{$\begin{array}{l}\text { Public Sphere } \\
\text { PEBs }\end{array}$} & \multicolumn{2}{|c|}{$\begin{array}{l}\text { Lighthouse } \\
\text { Private PEBs }\end{array}$} & \multicolumn{2}{|c|}{$\begin{array}{c}\text { Other Private } \\
\text { PEBs }\end{array}$} & \multirow{2}{*}{$\begin{array}{c}\text { PEB Type X Predictor } \\
\eta_{p}{ }^{2}\end{array}$} \\
\hline & $\mathbf{b}$ & $\eta_{p^{2}}$ & b & $\eta_{p^{2}}$ & $\mathbf{b}$ & $\eta_{p^{2}}$ & \\
\hline General environmental attitudes & $0.519^{* * *}$ & 0.076 & $0.400^{* * *}$ & 0.058 & $0.072 *$ & 0.005 & $0.029^{* * *}$ \\
\hline Green identity & $0.102 *$ & 0.004 & $0.221^{* * *}$ & 0.024 & $0.239^{* * *}$ & 0.062 & $0.004^{* *}$ \\
\hline Positive affect, feeling good & 0.007 & 0.000 & 0.053 & 0.002 & $0.058 *$ & 0.005 & $0.001 \mathrm{~ns}$ \\
\hline Awareness of consequences & $0.094^{* *}$ & 0.006 & $0.099 * * *$ & 0.009 & 0.033 & 0.002 & $0.002 \mathrm{~ns}$ \\
\hline Justifications & $\underset{* * *}{-0.177}$ & 0.012 & $\underset{* * *}{-0.202}$ & 0.020 & $-\underset{* * *}{-0.164}$ & 0.029 & $0.000 \mathrm{~ns}$ \\
\hline Prescriptive social norms & $0.145^{* * *}$ & 0.014 & 0.056 & 0.003 & 0.005 & 0.000 & $0.006^{* * *}$ \\
\hline Descriptive social norms & 0.010 & 0.000 & 0.060 & 0.002 & 0.010 & 0.000 & $0.001 \mathrm{~ns}$ \\
\hline Environmental knowledge & $0.335^{* * *}$ & 0.083 & $0.189^{* * *}$ & 0.035 & $0.079^{* * *}$ & 0.015 & $0.024^{* * *}$ \\
\hline Education level & $0.115 *$ & 0.005 & -0.004 & 0.000 & $-0.061 *$ & 0.004 & $0.005^{* *}$ \\
\hline Perceived behavioral control & 0.026 & 0.000 & $0.084^{*}$ & 0.004 & $0.062 *$ & 0.005 & $0.001 \mathrm{~ns}$ \\
\hline Age & 0.000 & 0.000 & 0.001 & 0.001 & $0.007^{* * *}$ & 0.042 & $0.008^{* * *}$ \\
\hline Gender & 0.043 & 0.001 & $0.185^{* * *}$ & 0.016 & $0.077^{* *}$ & 0.007 & $0.004 *$ \\
\hline Income & -0.057 & 0.003 & -0.016 & 0.000 & -0.012 & 0.000 & $0.001 \mathrm{~ns}$ \\
\hline Multiple $R^{2}\left(\right.$ corrected $\left.R^{2}\right)$ & 0.40 & $(0.40)$ & 0.41 & $(0.41)$ & 0.36 & $(0.35)$ & \\
\hline
\end{tabular}

${ }^{*} p \leq 0.001,{ }^{* *} p \leq 0.01,{ }^{* * *} p<0.05, \mathrm{~ns}=$ non-significant. Note. Names of predictors with significant effects aggregated over the three PEB-types (see Table 6) are printed in bold.

Finally, the repeated measurement ANOVA revealed a significant interaction effect for gender $\left(\eta^{2}=0.004, p<0.05\right)$, whereby females displayed significantly more private sphere PEBs than males (both lighthouse and non-lighthouse), whereas no gender effect was observed for public sphere behaviors. Additional t-tests conducted to compare males and females in relation to the three types of PEBs were consistent with this latter finding, as depicted in Table 8.

Table 8. Results of independent samples t-tests on gender differences in relation to the three types of PEBs (public, lighthouse private, non-lighthouse private) distinguished in this study.

\begin{tabular}{cccccccc}
\hline & Gender & $\mathbf{N}$ & $\mathbf{M}$ & SD & SE(M) & $t$-Value & $p$ \\
\hline \multirow{2}{*}{ Public sphere PEBs } & Male & 616 & 2.47 & 1.01 & 0.041 & -0.913 & $0.361^{\text {n.s. }}$ \\
& Female & 590 & 2.52 & 0.96 & 0.040 & & \\
\hline \multirow{2}{*}{ Lighthouse private PEBs } & Male & 616 & 3.95 & 0.90 & 0.036 & -5059 & $<0.001^{* * *}$ \\
& Female & 590 & 4.20 & 0.85 & 0.035 & & \\
\hline \multirow{2}{*}{ Other private PEBs } & Male & 616 & 4.73 & 0.58 & 0.023 & -3837 & $<0.001^{* * *}$ \\
& Female & 590 & 4.86 & 0.53 & 0.022 & & \\
\hline \multirow{7}{*}{ All PEBs } & Male & 616 & 4.00 & 0,60 & 0.024 & -4598 & $<0.0011^{* * *}$ \\
& Female & 590 & 4.14 & 0.56 & 0.023 & & \\
\hline
\end{tabular}

\section{Discussion}

The findings on determinants of different types of PEB and corresponding differences are discussed primarily, followed by the implications for the further development of a general framework and integrative models of PEB. Then, consequences and possible applications with regard to policy measures, communication and environmental education are addressed, followed by a discussion of limitations of this study and future research needs.

\subsection{Distinct Types of Peb and Their Determinants}

This study started from Stern's [20] general conceptual framework for environmental behavior models. By applying a PCA on a set of 23 PEBs, two principal components could be extracted that 
enabled the distinction of three types of PEBs: (i) public sphere behaviors that mainly indirectly impact the environment through social and political processes (as described by Stern); (ii) private sphere lighthouse PEBs that have a direct impact on the environment but also tend to be perceived by the social environment and thereby exert socially mediated impacts; and (iii) less socially salient (i.e., non-lighthouse) private sphere PEBs with a high level of privacy and direct impacts on the environment. Accordingly, Stern's [20] classification was extended by distinguishing between socially salient private PEBs that are noticeable, have a clear environmental orientation, and send a pro-environmental message to others from highly private (i.e., non-lighthouse) PEBs.

It turned out that general environmental attitudes proved to be more influential with respect to public sphere PEBs compared to both types of private sphere PEBs. This was expected because public sphere PEBs tend to be clearly and explicitly oriented towards achieving environmental and sustainability-oriented ends [20]. Hypothesis 1 was accordingly clearly confirmed by the data in line with previous empirical findings by Stern and colleagues [19], but partially inconsistent with a study by Ertz and colleagues [107]. However, the latter study addressed attitudes towards behaviors directly (ratings of importance and financial costs of the behaviors), whereas the current study measured general environmental attitudes. Therefore, it seems important to consider how attitudes are exactly measured and understood in future studies, which are needed to reconcile these findings.

Furthermore, environmental attitudes turned out to be significantly more influential in relation to the lighthouse private sphere PEBs than for the non-lighthouse private sphere PEBs. A possible explanation for this could be that environmental concerns are more in the foreground of the more socially salient lighthouse PEBs compared to less socially salient private PEBs, because the environmental significance of a behavior may increase the social salience of a behavior since environmental topics and concerns are of great contemporary societal interest. Another reason could be that the large social salience of the lighthouse PEBs could increase the consistency between environmental attitudes and these behaviors based on social identity or impression management considerations $[89,120,121]$. However, both possible explanations seem a bit speculative and need to be regarded with much caution as further research is needed to clarify which of them may be functional.

Considering Hypotheses 2-5, which addressed the influence of social norms on PEBs, the findings were quite heterogeneous. The descriptive norms did not prove to be a significant predictor of any of the three types of PEBs that were distinguished in this study at all. Hypotheses 2 and 4 were thus not confirmed by the data.

The subjectively perceived prescriptive pro-environmental social norms proved to be important determinants for engagement in public sphere PEBs, but showed no significant relation to either of the two types of private sphere PEBs. Accordingly, Hypotheses 3 was confirmed, whereas Hypothesis 5 had to be rejected.

Both types of private sphere behaviors seemed accordingly not to be influenced by social norms, which contradicts findings of previous studies including large meta-analyses on the TPB [50,51]. A reason for this could be that studies applying the TPB have usually not included explanatory variables such as environmental knowledge, green identity, and justifications, which resulted as powerful predictors in this research. Eventually, these additional powerful predictors made perceived descriptive and prescriptive social norms redundant for the explanation of variance in private sphere PEBs in this study.

Environmental knowledge resulted as the most important predictor of public sphere PEBs and was thus significantly more influential with respect to these public PEBs than with regard to both types of private PEBs. This finding is inconsistent with a finding by Liobikienè and Poškus [106], who found, on the contrary, action-related environmental knowledge to be significantly related to private sphere PEBs but not to public sphere PEBs. Different measures of knowledge may be underlying this seeming inconsistency as, contrary to the action-related knowledge assessed in the previous study, a general environmental knowledge measure was taken in this study. So, eventually, socio-political public sphere 
PEBs are influenced more strongly by general environmental knowledge, whereas more behavior specific knowledge is required for performing private sphere PEBs.

Green self-identity was a stronger predictor for both types of private PEBs than for public sphere PEBs. This finding suggests that private sphere PEBs are more closely related to an individual's green self-identity than public sphere PEBs, whereas strong pro-environmental attitudes are particularly important for politically supporting green values through public sphere actions and publicly noticeable private sphere lighthouse behaviors. However, it may be fruitful for future research to distinguish between a green self-identity referring to the private sphere (self-identity as a green consumer) and that referring to the public and political spheres-for example, a self-identity as a green pro-environmental communicator and activist, which combined together could ultimately represent a green citizenship self-identity [100,122].

A further important finding was that justifications of negative environmental behaviors were an equally strong negative determinant of all three types of PEBs, which confirms previous research suggesting that justifications should be integrated as a central structural component in psychological models of behavioral decision-making processes related to environmental behaviors [80-84].

A positive female gender effect on PEBs revealed in previous research $[102,103]$ was only observed for the two types of private sphere behaviors in this study. This finding may be related to a general underrepresentation of females in the political sphere $[123,124]$. However, females engage in both types of private sphere PEBs significantly more frequently than males.

An age effect was observed for less socially salient non-lighthouse private sphere behaviors; older people display such behaviors significantly more frequently than younger persons. However, no age effects were identified for more socially salient private lighthouse or politically oriented public sphere PEBs. The latter findings may seem surprising on first sight in light of the strong pro-environmental political engagement that young people in Switzerland evinced in the months before this survey - for example, as part of the Fridays for Future movement. However, one needs to consider that most pupils participating in the Fridays for Future demonstrations are presumably younger than 18 years old and could therefore not be included in the sample of participants drawn for this study.

\subsection{A Framework for Understanding Pro-Environmental Behaviors}

The explanative power of the integrative behavioral model considered in this study was represented by an adjusted multiple R-square value reflecting about $40 \%$ of the explained variance for public sphere and lighthouse private PEBs and 35\% for the non-lighthouse private sphere PEBs. These values surpass the shares of variance in environmental behavior that are typically explained by the TPB, which is currently the most widely applied environmental behavior model. For example, Armitage and Conner's [50] meta-analysis of 185 independent studies applying the TPB found that such models accounted for an average of $27 \%$ of the variance in diverse environmental behaviors.

A considerable higher proportion of explained variance was expected in the current study for various reasons. Firstly, in addition to TPB variables such as attitudes, perceived behavioral control, and subjectively perceived norms, further psychological predictor variables such as justifications, green self-identity, and environmental knowledge and control variables such as gender and age were considered. Secondly, the dependent variables were represented in aggregated behavioral scales, which have a higher reliability than single item behavior measures and therefore could be more accurately predicted. However, studies addressing PEBs in general terms also have some major limitations. Constructs such as perceived behavioral control, social norms, or justification can comprise highly behavior-specific aspects that can only be addressed in an encompassing and detailed manner if they are investigated in specific contexts. Therefore, studies on specific environmental behaviors (e.g., littering, biking to work) are needed to understand the mental models and perceptions underlying certain behaviors and derive corresponding recommendations and measures to facilitate and promote their performance [82,125]. However, studies like that presented 
here that aim to explain and better understand PEBs in general and different types of PEBs are important in order to create a fundamental knowledge base that is transferable and adaptable to diverse specific behavioral domains. A combination of research into different types of PEBs and research into specific PEBs enables an improved understanding of these interrelated levels, which seems helpful for developing interventions to modify environmental behaviors and promote environmentally-and sustainability—oriented actions.

\subsection{Implications for Policy, Communication, and Environmental Education}

Rapid environmental changes highlight a need to move towards more pro-environmental behaviors. The identification of PEB determinants can reveal factors that can be influenced to promote behavioral change for enhancing environmental protections and sustainable development. Because multiple determinants exist and different intervention forms and strategies may be effective to tackle different behavior determinants, a multi-level approach toward behavioral change involving intervention mapping seems desirable $[126,127]$. Such mapping should relate intervention methods and strategies to their effects on behavioral determinants and actual behaviors. The results presented in this study support the development of such mapping, as they help explain the determinants underlying certain types of behaviors. Accordingly, interventions aiming to promote social norms (such as social marketing techniques, use of group dynamics, and peer group pressure) may be more effective to promote public sphere and private lighthouse behaviors, whereas promoting a green identity may be more successful for changing highly private behaviors. Furthermore, it needs to be acknowledged that measures and approaches addressing the multiple psychological determinants of behaviors must not rely solely on exclusively psychological approaches. Rather, comprehensive intervention mapping should acknowledge that encompassing behavioral change strategies need to combine economic, policy, and technological changes with psychological methods such as education and communication. Various interventions aiming at distinct psychological determinants need to be concurrently applied in order to create synergies for desired behavior changes. For example, justifications for ecologically harmful alternative behaviors and negative attitudes towards PEBs are sometimes based on the high costs and extensive efforts required for achieving certain PEBs such as buying organic food or traveling by train (instead of a plane) for a holiday trip $[78,80,98]$. Therefore, economic interventions (incentives, pricing) and logistic measures should be combined with communication and educational activities to improve attitudes and counteract justifications in order to promote ecologically responsible travel modes and organic food consumption. Such examples also show that the development of measures for changing specific behaviors needs to be informed by specific contextual knowledge of the behavior in question. Nonetheless, some general policy implications can be derived from our results, which indicate that environmental knowledge, general environmental attitudes, green self-identity, and awareness of the consequences of our behavior are relevant determinants of PEBs that can be fostered through improved environmental communication, information, sensitization, and education $[64,128]$. Clearly, a more systemic perspective and a profound understanding between actions and their potential positive effects can help foster PEBs [97]. Experiential, constructivist, or project-based learning activities that actively engage learners in a supportive social context in which they experience autonomy and social recognition for their own competence and actions seem particularly suitable to synergistically promoting environmental attitudes and knowledge $[129,130]$. The social context merits special attention in such learning processes, as social interaction processes can motivate learning and help to convey sustainability-oriented social norms, skills, competencies, and environmentally positive social practices to individuals [125,131-135]. In addition, the promotion of motivations and competencies for environmental citizenship behavior in the public sphere is an important aspect that currently seems to be underrepresented in both research and education programs relative to private sphere behaviors [52].

The results of our study suggest that policies might need to differentially facilitate the three types of behaviors given the distinctions identified between the determinants of public sphere, private 
sphere lighthouse, and private non-lighthouse PEBs. Whereas public and private sphere lighthouse behaviors are both strongly influenced by environmental knowledge and general environmental attitudes, private non-lighthouse PEBs are less controlled by prescriptive social norms and more strongly driven by individuals' green identities. However, the influence of green identity on PEBs may not be unidirectional; via self-perception and the formation of habits, frequent performance of PEBs may in turn also promote green identity [125]. Accordingly, policy could promote green identities through incentives and the facilitation of PEBs, and it is important to offer options to enhance the implementation of green behaviors in this respect. Facilitating behaviors by removing barriers and restrictions and creating incentives and options may also be effective in overcoming the justification problem. Such measures seem promising as a means to complement communication and education approaches aiming to raise consciousness about the moral aspects of environmental behavior. It should be kept in mind that explicitly addressing justifications in environmental communication verbally may backfire, as they sometimes entail counterarguments that can be difficult to tackle and refute. Removing restrictions, creating better options, and establishing incentives for PEBs can more effectively counteract the root causes and claims of some justifications.

\subsection{Limitations and Future Research Needs}

One limitation of the current study is that, whereas some of the psychological predictor variables were measured by multiple item scales (general environmental attitudes, justifications), most psychological constructs were assessed through only one or two items. This distinction may have reduced the explanatory power of psychological constructs such as descriptive norms and positive affect, which were measured by only one item and found to be of minor importance as determinants of PEBs in this study. Future research should develop and employ scales for the measurement of all psychological constructs. Doing so was not feasible in this study, because it had to include some items serving other research purposes, and the number of items used to measure the predictor variables was therefore limited in order to not overload participants. For the same reason, the assessment of environmental knowledge relied on a single item measuring self-evaluated knowledge, which is a subjective measure that can be influenced by a social desirability and an overconfidence bias. A knowledge test comprised of multiple items is necessary to produce an objective measurement of environmental knowledge with satisfying reliability.

The measures applied in this study enabled the formulation of a model with satisfying explanative power. However, various further studies that preferably use more objective measures for environmental knowledge and more encompassing scales for measuring other predictors are needed to validate our findings and further develop environmental behavior models for different types of PEBs. In this context, the set of 23 PEBs could be enlarged in a future study. It is possible that a larger and (even) more diverse set of PEB items would result in the emergence of additional factors from a PCA so that additional PEB types and classification criteria could be identified. For example, Stern [20] suggested organizational behavior as a different type of environmentally significant behavior that may be distinguished and determined by specific predictors.

A further limitation of the present study concerns the measurement of the PEBs. Separate scales with sets of corresponding behavior items and acceptable Cronbach's alpha values were constructed for the three different types of PEBs (public sphere, lighthouse private sphere, non-lighthouse private). However, these scales measure self-reported behavior. Although such self-reports are usually substantially correlated with actual behavior, it is also known that the corresponding correlations are far from perfect and self-reports sometimes lack validity and may deviate from objectively observed behavior [55]. However, observing large sets of different behaviors of certain persons in different domains seems methodologically difficult. It seems more feasible to observe specific PEBs or PEBs in specific domains and connect those observations to an environmental behavior model. Multiple previous studies have searched for adequate models to explain specific behaviors (e.g., organic food purchases, recycling batteries) $[51,58,80,81]$; however, many of these works similarly relied 
on self-reported behavior. Therefore, more research that includes measures of observed behavior as dependent variable needs to be conducted to ensure that the psychological models possess a high external validity. Furthermore, the previous findings of studies on specific behaviors could be related to the typologies of PEBs developed by Stern [20] and extended in this study through an encompassing meta-analysis.

\section{Conclusions}

This study further elaborated the conceptualization of different types of environmental behaviors developed by Stern [20] by distinguishing between varying levels of social salience of private sphere behaviors. On this basis, the term of lighthouse PEBS was coined to denote private sphere behaviors that are highly noticeable in the social environment and thereby send a signal to others. At first sight, the notion of lighthouse private sphere behaviors may seem like an oxymoron because a lighthouse is everything but private. However, for example, if a homeowner of a family house in a small village makes the private decision to put up a large solar panel on their roof, this will be visible to others in the community and send a message indicative of the owner's positive environmental attitudes. In contrast, if the same homeowner takes short, rather cold showers rather than long hot ones without announcing this to others, then this is a highly private PEB. Such examples demonstrate that the seeming oxymoron of private lighthouse behavior does indeed make sense, as private sphere behaviors may actually involve different levels of privacy, and this concept may ultimately prove to be fruitful for the further development of theories and typologies of environmental behaviors.

Public sphere PEBs are a second focus of the typologies presented by Stern [20] and explored in this study, and the corresponding findings should raise the awareness of researchers and practitioners regarding specific aspects of these types of behavior. The authors perceive that previous research on environmental behavior has greatly focused on private sphere behaviors and that public sphere behaviors need to receive more attention in the future. Environmental citizenship behavior appears to be a promising concept connecting both public and private sphere PEBs and should accordingly be focused more strongly both in research and education [52].

Author Contributions: Both authors contributed to the planning and implementation of this study and to the development of the presented theoretical model. Both authors contributed to the statistical analyses, interpretation of findings and drafting of the article. However, R.H. was leading the statistical analyses and took over the larger part of drafting the article. All authors have read and agreed to the published version of the manuscript.

Funding: This research received no external funding.

Acknowledgments: We thank Silvia Hostettler and Livia Fritz from HERUS EPFL for valuable comments of a previous version of this article.

Conflicts of Interest: The authors declare no conflict of interest.

\section{References}

1. Mbow, H.-O.P.; Reisinger, A.; Canadell, J.; O'Brien, P. Special Report on Climate Change, Desertification, Land Degradation, Sustainable Land Management, Food Security, and Greenhouse Gas Fluxes in Terrestrial Ecosystems (SR2); IPCC: Geneva, Switzerland, 2017.

2. Tong, D.; Zhang, Q.; Zheng, Y.; Caldeira, K.; Shearer, C.; Hong, C.; Qin, Y.; Davis, S.J. Committed emissions from existing energy infrastructure jeopardize $1.5^{\circ} \mathrm{C}$ climate target. Nature 2019, 572, 373-377. [CrossRef] [PubMed]

3. Rosa, E.; Diekmann, A.; Dietz, T.; Jaeger, C. (Eds.) Human Footprints on the Global Environment: Threats to Sustainability; MIT Press: Cambridge, MA, USA, 2010.

4. Intergovernmental Panel on Climate Change. Global Warming of $1.5^{\circ} \mathrm{C}$. Inter-Governmental Panel on Climate Change (IPCC); IPCC: Geneva, Switzerland, 2018. Available online: http://www.ipcc.ch/report/sr15/ (accessed on 10 June 2020).

5. World Commission on Environment and Development. Our Common Future; Brundtland Report; Oxford University Press: Oxford, UK, 1987; ISBN 019282080X. 
6. Burns, T.R. The sustainability revolution: A societal paradigm shift? Sustainability 2012, 4, 1118-1134. [CrossRef]

7. Burns, T.R. Sustainable development: Agents, systems and the environment. Curr. Sociol. Rev. 2016, 64, 875-906. [CrossRef]

8. McManners, P.J. Adapt and Thrive: The Sustainable Revolution; Susta Press: London, UK, 2008; ISBN 0955736900.

9. D'Adamo, I.; Falcone, P.M.; Martin, M.; Rosa, P. A Sustainable Revolution: Let's Go Sustainable to Get Our Globe Cleaner. Sustainability 2020, 12, 4387. [CrossRef]

10. Ernst, L.; de Graaf-Van Dinther, R.E.; Peek, G.J.; Loorbach, D.A. Sustainable urban transformation and sustainability transitions; conceptual framework and case study. J. Clean. Prod. 2016, 112, 2988-2999. [CrossRef]

11. Lagerstedt Wadin, J.; Ahlgren, K.; Bengtsson, L. Joint business model innovation for sustainable transformation of industries - A large multinational utility in alliance with a small solar energy company. J. Clean. Prod. 2017, 160, 139-150. [CrossRef]

12. Lahtinen, S.; Yrjölä, M. Managing sustainability transformations: A managerial framing approach. J. Clean. Prod. 2019, 223, 815-825. [CrossRef]

13. Ringrose, P.S. Principles of sustainability and physics as a basis for the low-carbon energy transition. Petrol. Geosci. 2017, 23, 287-297. [CrossRef]

14. Sanders, N.R.; Wood, J.D. Foundations of Sustainable Business: Theory, Function, and Strategy; John Wiley \& Sons: Hoboken, NJ, USA, 2015; ISBN 978-1-118-44104-6.

15. Gallagher, V.C.; Hrivnak, M.W.; Valcea, S.; Mahoney, C.B.; LaWong, D. A comprehensive three-dimensional sustainability measure: The 'missing $\mathrm{P}^{\prime}$ of 'people'-A vital stakeholder in sustainable development. Corp. Soc. Responsib. Environ. Manag. 2018, 25, 772-787. [CrossRef]

16. Gifford, R. The dragons of inaction: Psychological barriers that limit climate change mitigation and adaptation. Am. Psychol. 2011, 66, 290-302. [CrossRef]

17. Shittu, O. Emerging sustainability concerns and policy implications of urban household consumption: A systematic literature review. J. Clean. Prod. 2020, 246, 119034. [CrossRef]

18. Valor, C.; Antonetti, P.; Merino, A. The relationship between moral competences and sustainable consumption among higher education students. J. Clean. Prod. 2020, 248, 119161. [CrossRef]

19. Stern, P.C.; Dietz, T.; Abel, T.; Guagnano, G.A.; Kalof, L. A value-belief-norm theory of support for social movements: The case of environmental concern. Hum. Ecol. Rev. 1999, 6, 81-97.

20. Stern, P.C. Toward a coherent theory of environmentally significant behavior. J. Soc. Issues 2000, 56, 407-424. [CrossRef]

21. Partelow, S. Coevolving Ostrom's social-ecological systems (SES) framework and sustainability science: Four key co-benefits. Sustain. Sci. 2016, 11, 399-410. [CrossRef]

22. Ostrom, E. A general framework for analyzing sustainability of social-ecological systems. Science 2009, 325, 419-422. [CrossRef]

23. Ostrom, E.; Cox, M. Moving beyond panaceas: A multi-tiered diagnostic approach for social-ecological analysis. Environ. Conserv. 2010, 37, 451-463. [CrossRef]

24. Scholz, R.W. Environmental Literacy in Science and Society: From Knowledge to Decisions; Cambridge University Press: Cambridge, UK, 2011. [CrossRef]

25. Stauffacher, M.; Walter, A.I.; Lang, D.J.; Wiek, A.; Scholz, R.W. Learning to research environmental problems from a functional socio-cultural constructivism perspective: The transdisciplinary case study approach. Int. J. Sustain. High. Educ. 2006, 7, 252-275. [CrossRef]

26. Lewin, K. Field Theory in Social Sciences; Harper \& Brothers: New York, NY, USA, 1951.

27. Schwartz, S.H. Normative influences on altruism. Adv. Exp. Soc. Psychol. 1977, 10, 221-279. [CrossRef]

28. Fang, W.-T.; Chiang, Y.-T.; Ng, E.; Lo, J.-C. Using the Norm Activation Model to Predict the Pro-Environmental Behaviors of Public Servants at the Central and Local Governments in Taiwan. Sustainability 2019, 11, 3712. [CrossRef]

29. Liu, Y.; Sheng, H.; Mundorf, N.; Redding, C.; Ye, Y. Integrating Norm Activation Model and Theory of Planned Behavior to Understand Sustainable Transport Behavior: Evidence from China. Int. J. Environ. Res. Public Health 2017, 14, 1593. [CrossRef] [PubMed] 
30. Shi, H.; Fan, J.; Zhao, D. Predicting household pm2.5-reduction behavior in Chinese urban areas: An integrative model of theory of planned behavior and norm activation theory. J. Clean. Prod. 2017, 145, 64-73. [CrossRef]

31. Shin, Y.H.; Im, J.; Jung, S.E.; Severt, K. The theory of planned behavior and the norm activation model approach to consumer behavior regarding organic menus. Int. J. Hosp. Manag. 2018, 69, 21-29. [CrossRef]

32. Wittenberg, I.; Blobaum, A.; Matthies, E. Environmental motivations for energy use in PV households: Proposal of a modified norm activation model for the specific context of PV households. J. Environ. Psychol. 2018, 55, 110-120. [CrossRef]

33. Ibrahim, A.; Knox, K.; Rundle-Thiele, S.; Arli, D. Segmenting a Water Use Market: Theory of Interpersonal Behavior Insights. Soc. Market Q. 2018, 24, 3-17. [CrossRef]

34. Triandis, H.C. Interpersonal Behaviour; Brooks/Cole: Monterey, CA, USA, 1977; ISBN 081850188X.

35. Triandis, H.C. Values, attitudes, and interpersonal behavior. In Nebraska Symposium of Motivation, 1980: Cognitive Processes; Howe, H.E., Jr., Page, M., Eds.; University of Nebraska Press: Lincoln, NE, USA, 1980; Volume 27, pp. 195-259. ISBN 978-0-783-766218.

36. Bamberg, S.; Möser, G. Twenty years after Hines, Hungerford, and Tomera: A new meta-analysis of psycho-social determinants of pro-environmental behaviour. J. Environ. Psychol. 2007, 27, 14-25. [CrossRef]

37. Chao, Y.L. Predicting people's environmental behavior: Theory of planned behaviour and model of responsible environmental behaviour. Environ. Educ. Res. 2012, 18, 437-461. [CrossRef]

38. Hines, J.M.; Hungerford, H.R.; Tomera, A.N. Analysis and synthesis of research on responsible environmental behaviour: A meta-analysis. J. Environ. Educ. 1987, 18,1-8. [CrossRef]

39. Thøgersen, J.; Ölander, F. The dynamic interaction of personal norms and environment-friendly buying behaviour: A panel study. J. Appl. Soc. Psychol. 2006, 36, 1758-1780. [CrossRef]

40. Zhang, R.; Lang, C. Application of motivation-opportunity-ability theory in the consumption of eco-fashion products: Were Chinese consumers underestimated? In Chinese Consumers and the Fashion Market; Xu, Y., Chi, T., Su, J., Eds.; Springer Series in Fashion Business; Springer: Singapore, 2018; pp. 119-141. ISBN 978-9-8113-4148-9.

41. Cialdini, R.B.; Reno, R.R.; Kallgren, C.A. A focus theory of normative conduct: Recycling the concept of norms to reduce littering in public places. J. Pers. Soc. Psychol. 1990, 58, 1015-1026. [CrossRef]

42. Hamann, K.R.S.; Reese, G.; Seewald, D.; Loeschinger, D.C. Affixing the theory of normative conduct (to your mailbox): Injunctive and descriptive norms as predictors of anti-ads sticker use. J. Environ. Psychol. 2015, 44, 1-9. [CrossRef]

43. Reno, R.R.; Cialdini, R.B.; Kallgren, C.A. The trans-situational influence of social norms. J. Pers. Soc. Psychol. 1993, 64, 104-112. [CrossRef]

44. Kiatkawsin, K.; Han, H. Young travelers' intention to behave pro-environmentally: Merging the value-belief-norm theory and the expectancy theory. Tourism Manag. 2017, 59, 76-88. [CrossRef]

45. Ajzen, I. The theory of planned behavior. Organ. Behav. Human Dec. 1991, 50, 179-211. [CrossRef]

46. Ajzen, I. Values, attitudes, and behavior. In Methods, Theories, and Empirical Applications in the Social Sciences; Salzborn, S., Davidov, E., Reinecke, J., Eds.; VS Verlag für Sozialwissenschafte: Wiesbaden, Germany, 2012; pp. 33-38. ISBN 978-3-5311-7130-2.

47. Sun, W. Toward a theory of ethical consumer intention formation: Re-extending the theory of planned behavior. AMS Rev. 2019, 1-19. [CrossRef]

48. Morten, A.; Gatersleben, B.; Jessop, D.C. Staying grounded? Applying the theory of planned behavior to explore motivations to reduce air travel. Transport. Res. F Traf. 2018, 55, 297-305. [CrossRef]

49. Riebl, S.K.; Estabrooks, P.A.; Dunsmore, J.C.; Savla, J.; Frisard, M.I.; Dietrich, A.M.; Peng, Y.; Zhang, X.; Davy, B.M. A systematic literature review and metaanalysis: The Theory of Planned Behavior's application to understand and predict nutrition-related behaviors in youth. Eat. Behav. 2015, 18, 160-178. [CrossRef]

50. Armitage, C.J.; Conner, M. Efficacy of the theory of planned behaviour: A meta-analytic review. Br. J. Soc. Psychol. 2001, 40, 471-499. [CrossRef]

51. Scalco, A.; Noventa, S.; Sartori, R.; Ceschi, A. Predicting organic food consumption: A meta-analytic structural equation model based on the theory of planned behavior. Appetite 2017, 112, 235-248. [CrossRef]

52. Hadjichambis, A.C.; Reis, P.; Paraskeva-Hadjichambi, D.; Činčera, J.; Boeve-de Pauw, J.; Gericke, N.; Knippels, M.-C. (Eds.) Conceptualizing Environmental Citizenship for 21st Century Education; Springer Nature: Cham, Switzerland, 2020; ISBN 978-3-0302-02484. 
53. Arnold, O.; Kibbe, A.; Hartig, T.; Kaiser, F.G. Capturing the environmental impact of individual lifestyles: Evidence of the criterion validity of the general ecological behavior scale. Environ. Behav. 2018, 50, 350-372. [CrossRef]

54. Otto, S.; Evans, G.W.; Moon, M.J.; Kaiser, F.G. The development of children's environmental attitude and behavior. Global Environ. Chang. 2019, 58, 101947. [CrossRef]

55. Huffman, A.H.; van der Werff, B.R.; Henning, J.B.; Watrous-Rodriguez, K. When do recycling attitudes predict recycling? An investigation of self-reported versus observed behavior. J. Environ. Psychol. 2014, 38, 262-270. [CrossRef]

56. Lavelle, M.J.; Fahy, F. What's consuming Ireland? Exploring expressed attitudes and reported behaviours towards the environment and consumption across three case study locations on the island of Ireland. Ir. Geogr. 2016, 49, 29-54. [CrossRef]

57. Gkargkavouzi, A.; Halkos, G.; Matsiori, S.A. Multi-dimensional measure of environmental behavior: Exploring the predictive power of connectedness to nature, ecological worldview and environmental concern. Soc. Indic. Res. 2019, 143, 859-879. [CrossRef]

58. Johe, M.H.; Bhullar, N. To buy or not to buy: The roles of self-identity, attitudes, perceived behavioral control and norms in organic consumerism. Ecol. Econ. 2016, 128, 99-105. [CrossRef]

59. Mead, G. Mind, Self and Society; University of Chicago Press: Chicago, IL, USA, 1934.

60. Tajfel, H. Social Identity and Intergroup Relations; Cambridge University Press: Cambridge, UK, 1982.

61. Davis, J.L.; Le, B.; Coy, A.E. Building a model of commitment to the natural environment to predict ecological behavior and willingness to sacrifice. J. Environ. Psychol. 2011, 31, 257-265. [CrossRef]

62. Gardner, B.; de Bruijn, G.J.; Lally, P. Habit, identity, and repetitive action: A prospective study of binge-drinking in UK students. Br. J. Health Psych. 2012, 17, 565-581. [CrossRef]

63. Hansmann, R.; Laurenti, R.; Mehdi, T.; Binder, C.R. Determinants of pro-environmental behavior: A comparison of university students and staff from diverse faculties at a Swiss University. J. Clean. Prod. 2020, 268, 121864. [CrossRef]

64. Jackson, T. Motivating Sustainable Consumption: A Review of Evidence on Consumer Behaviour and Behavioural Change; A Report to the Sustainable Development Research Network; Centre for Environmental Strategies, University of Surrey: Guildford, UK, 2005.

65. Sparks, P.; Shepherd, R. Self-identity and the theory of planned behavior: Assessing the role of identification with "green consumerism". Soc. Psychol. Quart. 1992, 55, 388-399. [CrossRef]

66. Whitmarsh, L.; O'Neill, S. Green identity, green living? The role of pro-environmental self-identity in determining consistency across diverse pro-environmental behaviours. J. Environ. Psychol. 2010, 30, 305-314. [CrossRef]

67. Nisbet, E.K.; Zelenski, J.M. Underestimating nearby nature: Affective forecasting errors obscure the happy path to sustainability. Psychol. Sci. 2011, 22, 1101-1106. [CrossRef] [PubMed]

68. Taufik, D.; Bolderdijk, J.; Steg, L. Acting green elicits a literal warm glow. Nat. Clim. Change 2015, 5, 37-40. [CrossRef]

69. Van der Linden, S. Warm glow is associated with low- but not high-cost sustainable behaviour. Nat. Sustain. 2018, 1, 28-30. [CrossRef]

70. Bandura, A. Social Foundations of Thought and Action: A Social-Cognitive Theory; Prentice-Hall: Upper Saddle River, NJ, USA, 1986.

71. Bandura, A. Social cognitive theory: An agentic perspective. Annu. Rev. Psychol. 2000, 52, 1-26. [CrossRef]

72. Bandura, A. Health promotion by social cognitive means. Health Educ. Behav. 2004, 31, 143-164. [CrossRef]

73. Sykes, G.M.; Matza, D. Techniques of neutralization: A theory of delinquency. Am. Sociol. Rev. 1957, 22, 664-670. [CrossRef]

74. Copes, H. Societal attachments, offending frequency, and techniques of neutralization. Deviant Behav. 2003, 24, 101-127. [CrossRef]

75. Costello, B.J. Techniques of neutralization and self-esteem: A critical test of social control and neutralization theory. Deviant Behav. 2000, 21, 307-329. [CrossRef]

76. Zhang, H.; Chen, W.; Zhang, Y.; Buhalis, D.; Lu, L. National park visitors' car-use intention: A norm-neutralization model. Tourism Manag. 2018, 69, 97-108. [CrossRef]

77. Chatzidakis, A.; Hibbert, S.A.; Smith, A. Why people don't take their concerns about fair trade to the supermarket: The role of neutralisation. J. Bus. Ethics 2007, 74, 89-100. [CrossRef] 
78. Diekmann, A.; Preisendörfer, P. Persönliches umweltverhalten. Diskrepanzen zwischen anspruch und wirklichkeit. Kolner Z. Soziol. Soz. 1992, 44, 226-251. [CrossRef]

79. Fritsche, I. Die Erhebung von Rechtfertigungen umweltschädigenden verhaltens: Eine experimentelle studie zur validität der fragebogentechnik. Umweltpsychologie 1999, 3, 68-80.

80. Hansmann, R.; Baur, I.; Binder, C.R. Increasing organic food consumption: An integrating model of drivers and barriers. J. Clean. Prod. 2020, 275, 123058. [CrossRef]

81. Hansmann, R.; Bernasconi, P.; Smieszek, T.; Loukopoulos, P.; Scholz, R.W. Justifications and self-organization as determinants of recycling behavior: The case of used batteries. Resour. Conserv. Recycl. 2006, 47, 133-159. [CrossRef]

82. Hansmann, R.; Steimer, N. Linking an integrative behavior model to elements of environmental campaigns: An analysis of face-to-face communication and posters against littering. Sustainability 2015, 7, 6937-6956. [CrossRef]

83. Hansmann, R.; Steimer, N. Subjective reasons for littering: A self-serving attribution bias as justification process in an environmental behaviour model. Environ. Res. Eng. Manag. 2017, 73, 8-19. [CrossRef]

84. Schahn, J.; Dinger, J.; Bohner, G. Rationalisierungen und neutralisationen als rechtfertigungsstrategien: Ein vergleich zwischen umwelt- und delinquenzbereich. Z. für Differentielle und Diagnostische Psychologie 1995, 16, 177-194.

85. De Witt Huberts, J.C.; Evers, C.; De Ridder, D.T.D. License to sin: Self-licensing as a mechanism underlying hedonic consumption. Eur. J. Soc. Psychol. 2012, 42, 490-496. [CrossRef]

86. De Witt Huberts, J.C.; Evers, C.; De Ridder, D.T.D. “Because I am worth it” A theoretical framework and empirical review of a justification-based account of self-regulation failure. Pers. Soc. Psychol. Rev. 2014, 18, 119-138. [CrossRef] [PubMed]

87. De Witt Huberts, J.C.; Evers, C.; DeRidder, D.T.D. Thinking before sinning: Reasoning processes in hedonic consumption. Front. Psychol. 2014, 5, 1268. [CrossRef]

88. Taylor, C.; Webb, T.L.; Sheeran, P. 'I deserve a treat!': Justifications for indulgence undermine the translation of intentions into action. Br. J. Soc. Psychol. 2014, 53, 501-520. [CrossRef] [PubMed]

89. Farrow, K.; Grolleau, G.; Ibanez, L. Social norms and pro-environmental behavior: A review of the evidence. Ecol. Econ. 2017, 140, 1-13. [CrossRef]

90. Crott, H.W.; Hansmann, R. Informative intervention to improve normative functioning and output of groups. Swiss J. Psychol. 2003, 62, 177-193. [CrossRef]

91. Crott, H.W.; Werner, J. The norm-information-distance model: A stochastic approach to preference change in group interaction. J. Exp. Soc. Psychol. 1994, 30, 68-95. [CrossRef]

92. Deutsch, M.; Gerard, H.B. A study of normative and informational social influence upon individual judgement. J. Abnorm. Soc. Psych. 1955, 51, 629-636. [CrossRef]

93. Levine, J.M. (Ed.) Group Processes; Frontiers of Social Psychology; Psychology Press: New York, NY, USA; Taylor and Francis Group: London, UK, 2013; Volume 18.

94. Paulus, P.B. (Ed.) Psychology of Group Influence, 2nd ed.; Psychology Press: New York, NY, USA; Taylor and Francis Group: London, UK, 2015.

95. Kollmuss, A.; Agyeman, J. Mind the gap: Why do people act environmentally and what are the barriers to pro-environmental behavior? Environ. Educ. Res. 2002, 8, 239-260. [CrossRef]

96. Vicente-Molina, M.A.; Fernández-Sáinz, A.; Izagirre-Olaizola, J. Environmental knowledge and other variables affecting pro-environmental behaviour: Comparison of university students from emerging and advanced countries. J. Clean. Prod. 2013, 61, 130-138. [CrossRef]

97. Zsóka, A.; Szerényi, Z.M.; Széchy, A.; Kocsis, T. Greening due to environmental education? Environmental knowledge, attitudes, consumer behavior and everyday pro-environmental activities of Hungarian high school and university students. J. Clean. Prod. 2013, 48, 126-138. [CrossRef]

98. Di Vita, G.; Pappalardo, G.; Chinnici, G.; La Via, G.; D’Amico, M. Not everything has been still explored: Further thoughts on additional price for the organic wine. J. Clean. Prod. 2019, 231, 520-528. [CrossRef]

99. Wier, M.; Jensen, K.O.; Andersen, L.M.; Millock, K. The character of demand in mature organic food markets: Great Britain and Denmark compared. Food Policy 2008, 33, 406-421. [CrossRef] 
100. Goldman, D.; Hansmann, R.; Činčera, J.; Radović, V.; Telešienè, A.; Balžekienė, A.; Vávra, J. Education for environmental citizenship and responsible environmental behavior. In Conceptualizing Environmental Citizenship for 21st Century Education; Hadjichambis, A.C., Reis, P., Paraskeva-Hadjichambi, D., Činčera, J., Boeve-de Pauw, J., Gericke, N., Knippels, M.-C., Eds.; Springer Nature: Cham, Switzerland, 2020; pp. 115-137. ISBN 978-3-0302-02484.

101. Briscoe, M.D.; Givens, J.E.; Olson Hazboun, S.; Krannich, R.S. At home, in public, and in between: Gender differences in public, private and transportation pro-environmental behaviors in the US Intermountain West. Environ. Sociol. 2019, 5, 374-392. [CrossRef]

102. Chan, H.-W.; Pong, V.; Tam, K.-P. Cross-national variation of gender differences in environmental concern: Testing the sociocultural hindrance hypothesis. Environ. Behav. 2019, 51, 81-108. [CrossRef]

103. Chekima, B.C.; Syed Khalid Wafa, S.A.W.; Igau, O.A.; Chekima, S.; Sondoh, S.L. Examining green consumerism motivational drivers: Does premium price and demographics matter to green purchasing? J. Clean. Prod. 2016, 112, 3436-3450. [CrossRef]

104. Chiang, Y.-T.; Fang, W.-T.; Kaplan, U.; Ng, E. Locus of Control: The Mediation Effect between Emotional Stability and Pro-Environmental Behavior. Sustainability 2019, 11, 820. [CrossRef]

105. Milfont, T.L.; Sibley, C.G. The big five personality traits and environmental engagement: Associations at the individual and societal level. J. Environ. Psychol. 2012, 32, 187-195. [CrossRef]

106. Liobikienè, G.; Poškus, M.S. The Importance of Environmental Knowledge for Private and Public Sphere Pro-Environmental Behavior: Modifying the Value-Belief-Norm Theory. Sustainability 2019, 11, 3324. [CrossRef]

107. Ertz, M.; Karakas, F.; Sarigöllü, E. Exploring pro-environmental behaviors of consumers: An analysis of contextual factors, attitude, and behaviors. J. Bus. Res. 2016, 69, 3971-3980. [CrossRef]

108. Huang, H. Media use, environmental belies, self-efficacy, and pro-environmental behavior. J. Bus. Res. 2016, 69, 2206-2212. [CrossRef]

109. Tam, K.-P.; Chan, H.-W. Environmental concern has a weaker association with pro-environmental behavior in some societies than others: A cross-cultural psychology perspective. J. Environ. Psychol. 2017, 53, $213-223$. [CrossRef]

110. Kilbourne, W.; Pickett, G. How materialism affects environmental beliefs, concern, and environmentally responsible behavior. J. Bus. Res. 2008, 61, 885-893. [CrossRef]

111. Hanna, P.; Kantenbacher, J.; Cohen, S.; Gössling, S. Role model advocacy for sustainable transport. Transport. Res. Part D Transp. Environ. 2018, 61 Pt B, 373-382. [CrossRef]

112. Stern, M.J.; Frensley, B.T.; Powell, R.B.; Ardoin, N.M. What difference do role models make? Investigating outcomes at a residential environmental education center. Environ. Educ. Res. 2018, 24, 818-830. [CrossRef]

113. Asch, S.E. Studies of independence and conformity: I. A minority of one against a unanimous majority. Psychol. Monogr. Gen. A 1956, 70, 1-70. [CrossRef]

114. Cialdini, R.B.; Goldstein, N.J. Social influence: Compliance and conformity. Annu. Rev. Psychol. 2004, 55, 591-621. [CrossRef] [PubMed]

115. Sowden, S.; Koletsi, S.; Lymberopoulos, E.; Militaru, E.; Catmur, C.; Bird, G. Quantifying compliance and acceptance through public and private social conformity. Conscious. Cogn. 2018, 65, 359-367. [CrossRef] [PubMed]

116. Diekmann, A.; Preisendörfer, P. Umweltsoziologie. Eine Einführung; Rowohlt: Hamburg, Germany, 2001; ISBN 978-3-4995-55954.

117. Diekmann, A.; Meyer, R.; Mühlemann, C.; Diem, A. Schweizer Umweltsurvey 2007: Analysen und Ergebnisse-Bericht für das Bundesamt für Statistik (BFS) und das Bundesamt für Umwelt (BAFU); ETH Zürich, Professur für Soziologie: Zurich, Switzerland, 2009.

118. Bortz, J. Statistik für Sozialwissenschaftler, 5th ed.; Springer: Berlin/Heidelberg, Germany, 1999; ISBN 978-3-662-10031-8.

119. Guadagnoli, E.; Velicer, W.F. Relation of Sample Size to the Stability of Component Patterns. Psychol. Bull. 1988, 103, 265-275. [CrossRef]

120. Hogg, M.A.; Smith, J.R. Attitudes in social context: A social identity perspective. Eur. Rev. Soc. Psychol. 2007, 18, 89-131. [CrossRef]

121. Vermeir, I.; Verbeke, W. Sustainable food consumption: Exploring the consumer "attitude-behavioral intention" gap. J. Agric. Environ. Ethics 2006, 19, 169-194. [CrossRef] 
122. Parra, G.; Hansmann, R.; Hadjichambis, A.C.; Goldman, D.; Paraskeva-Hadjichambi, D.; Sund, P.; Sund, L.; Gericke, N.; Conti, D. Education for environmental citizenship and education for sustainability. In Conceptualizing Environmental Citizenship for 21st Century Education; Hadjichambis, A.C., Reis, P., Paraskeva-Hadjichambi, D., Činčera, J., Boeve-de Pauw, J., Gericke, N., Knippels, M.-C., Eds.; Springer Nature: Cham, Switzerland, 2020; pp. 149-160. ISBN 978-3-0302-02484.

123. Celis, K.; Lovenduski, J. Power struggles: Gender equality in political representation. Eur. J. Politics Gend. 2018, 1, 149-166. [CrossRef]

124. Kittilson, M.C.; Schwindt-Bayer, L. The Gendered Effects of Electoral Institutions: Political Engagement and Participation; Oxford University Press: New York, NY, USA, 2012; ISBN 978-0-1996-08607.

125. Kaplan, S.; Kaplan, R. Creating a larger role for environmental psychology: The reasonable person model as an integrative framework. J. Environ. Psychol. 2009, 29, 329-339. [CrossRef]

126. Bartholomew Eldredge, L.K.; Markham, C.M.; Ruiter, R.A.C.; Fernàndez, M.E.; Kok, G.; Parcel, G.S. Planning Health Promotion Programs, 4th ed.; John Wiley \& Sons: Hoboken, NJ, USA, 2016; ISBN 978-1-1190-35497.

127. Kok, G.; Gottlieb, N.H.; Peters, G.-J.Y.; Dolan Mullen, P.; Parcel, G.S.; Ruiter, R.A.C.; Fernández, M.E.; Markham, C.; Bartholomew, L.K. A taxonomy of behaviour change methods: An intervention mapping approach. Health Psychol. Rev. 2016, 10, 297-312. [CrossRef] [PubMed]

128. Varela-Candamio, L.; Novo-Corti, I.; García-Alvarez, M.T. The importance of environmental education in the determinants of green behavior: A meta-analysis approach. J. Clean. Prod. 2018, 170, 1565-1578. [CrossRef]

129. Deci, E.L.; Ryan, R.M. Self-determination theory: A macrotheory of human motivation, development, and health. Can. Psychol. 2008, 49, 182. [CrossRef]

130. Greaves, C.J.; Sheppard, K.E.; Abraham, C.; Hardeman, W.; Roden, M.; Evans, P.H.; Schwarz, P. Systematic review of reviews of intervention components associated with increased effectiveness in dietary and physical activity interventions. BMC Public Health 2011, 11, 119. [CrossRef] [PubMed]

131. Fry, P.; Thieme, S. A social learning video method: Identifying and sharing successful transformation knowledge for sustainable soil management in Switzerland. Soil Use Manag. 2019, 35, 185-194. [CrossRef]

132. Hansmann, R. "Sustainability learning": An introduction to the concept and its motivational aspects. Sustainability 2010, 2, 2873-2897. [CrossRef]

133. Vare, P.; Scott, W.A.H. Learning for a change: Exploring the relationship between education and sustainable development. J. Educ. Sustain. Dev. 2007, 1, 191-198. [CrossRef]

134. Barth, M.; Michelsen, G. Learning for change: An educational contribution to sustainability science. Sustain. Sci. 2013, 8, 103-119. [CrossRef]

135. Barth, M.; Godemann, J.; Rieckmann, M.; Stoltenberg, U. Developing key competencies for sustainable development in higher education. Int. J. Sustain. High. Educ. 2007, 8, 416-430. [CrossRef]

Publisher's Note: MDPI stays neutral with regard to jurisdictional claims in published maps and institutional affiliations.

(C) 2020 by the authors. Licensee MDPI, Basel, Switzerland. This article is an open access article distributed under the terms and conditions of the Creative Commons Attribution (CC BY) license (http://creativecommons.org/licenses/by/4.0/). 